\title{
Putting time into space: the temporal coherence of spatial applications in the housing market
}

\section{DOI:}

10.1016/j.regsciurbeco.2016.03.001

\section{Document Version}

Accepted author manuscript

Link to publication record in Manchester Research Explorer

\section{Citation for published version (APA):}

Thanos, S., Dubé, J., \& Legros, D. (2016). Putting time into space: the temporal coherence of spatial applications in the housing market. Regional Science and Urban Economics, 58, 78-88.

https://doi.org/10.1016/j.regsciurbeco.2016.03.001

\section{Published in:}

Regional Science and Urban Economics

\section{Citing this paper}

Please note that where the full-text provided on Manchester Research Explorer is the Author Accepted Manuscript or Proof version this may differ from the final Published version. If citing, it is advised that you check and use the publisher's definitive version.

\section{General rights}

Copyright and moral rights for the publications made accessible in the Research Explorer are retained by the authors and/or other copyright owners and it is a condition of accessing publications that users recognise and abide by the legal requirements associated with these rights.

\section{Takedown policy}

If you believe that this document breaches copyright please refer to the University of Manchester's Takedown Procedures [http://man.ac.uk/04Y6Bo] or contact uml.scholarlycommunications@manchester.ac.uk providing relevant details, so we can investigate your claim.

\section{OPEN ACCESS}




\section{Accepted Manuscript}

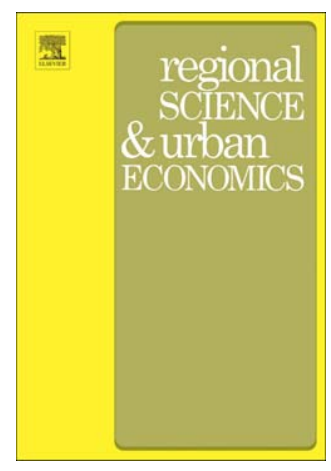

PII:

S0166-0462(16)00012-0

Putting Time into Space: The Temporal Coherence of Spatial Applications in the Housing Market

Sotirios Thanos, Jean Dubé, Diègo Legros

DOI:

doi: 10.1016/j.regsciurbeco.2016.03.001

Reference: $\quad$ REGEC 3170

To appear in: $\quad$ Regional Science and Urban Economics

Received date: 6 January 2015

Revised date: $\quad 26$ October 2015

Accepted date: 5 March 2016

Please cite this article as: Thanos, Sotirios, Dubé, Jean, Legros, Diègo, Putting Time into Space: The Temporal Coherence of Spatial Applications in the Housing Market, Regional Science and Urban Economics (2016), doi: 10.1016/j.regsciurbeco.2016.03.001

This is a PDF file of an unedited manuscript that has been accepted for publication. As a service to our customers we are providing this early version of the manuscript. The manuscript will undergo copyediting, typesetting, and review of the resulting proof before it is published in its final form. Please note that during the production process errors may be discovered which could affect the content, and all legal disclaimers that apply to the journal pertain. 
Title: Putting Time into Space: The Temporal Coherence of Spatial Applications in the Housing Market

Article Type: Full Length Article

Keywords: Housing market; Hedonic pricing; Spatial Econometrics; Spatio-temporal; Expectations; STAR; SAR;

First and Corresponding Author: Dr. Sotirios Thanos, PhD;

Corresponding Author's Affiliation: School of Environment, Education \& Development, University of Manchester

Corresponding Author's contact information: Humanities Bridgeford Street, University of Manchester, Manchester, M13 9PL, UK; email:sotirios.thanos@manchester.ac.uk, tel: +44(0)161-306-6439

Second Author: Professor Jean Dubé, PhD;

Second Author's Affiliation: Centre de Recherche en Aménagement et Développement, Laval University

Third Author: Dr. Diègo Legros, PhD;

Third Author's Affiliation: Laboratoire d'Économie et de Gestion, Université de Bourgogne Order of Authors: Sotirios Thanos; Jean Dubé; Diègo Legros;

Abstract

Relationships between past events, future expectations and present decisions, typically examined through a temporal prism within applied economics, have been lately moving to the spatial dimension through spatial econometrics. However, violations of the "arrow of time", and thus causality, have been identified in spatial econometric techniques applied to spatiotemporal data consisting of observations each at a specific location and distinct moment in time. A comprehensive review classifies for the first time several redresses to this issue in a currently fragmented literature. This paper puts back the temporal dimension into spatial Hedonic Pricing models through a unique specification of a spatio-temporal model that successfully isolates three distinct effects. First, past sale prices affecting current prices, which exemplifies the "sales comparison" approach. Second, a contemporaneous peer effect that is occurring within the narrow time frame of interaction between market participants prior to a sale. Third, the signals of sellers' expectations are captured in the asking prices of other houses not yet sold, while the buyer is active in the market. This affects the final sale price, due to strategic behavior and anchoring. This is the first instance that effects other than the own asking price can be handled in such models. In "boom" market conditions, this mechanism introduces the expectation of increasing prices to the hedonic price function, potentially contributing to housing market "bubble" propagation. 


\title{
Putting Time into Space: The Temporal Coherence of Spatial Applications in the Housing Market
}

\begin{abstract}
Relationships between past events, future expectations and present decisions, typically examined through a temporal prism within applied economics, have been lately moving to the spatial dimension through spatial econometrics. However, violations of the "arrow of time", and thus causality, have been identified in spatial econometric techniques applied to spatiotemporal data consisting of observations each at a specific location and distinct moment in time. A comprehensive review classifies for the first time several redresses to this issue in a currently fragmented literature. This paper puts back the temporal dimension into spatial Hedonic Pricing models through a unique specification of a spatio-temporal model that successfully isolates three distinct effects. First, past sale prices affecting current prices, which exemplifies the "sales comparison" approach. Second, a contemporaneous peer effect that is occurring within the narrow time frame of interaction between market participants prior to a sale. Third, the signals of sellers' expectations are captured in the asking prices of other houses not yet sold, while the buyer is active in the market. This affects the final sale price, due to strategic behavior and anchoring. This is the first instance that effects other than the own asking price can be handled in such models. In "boom" market conditions, this mechanism introduces the expectation of increasing prices to the hedonic price function, potentially contributing to housing market "bubble" propagation.
\end{abstract}




\section{Introduction}

Relationships between expectations about the future, past events and decisions in the present have been a longstanding theme in the economic literature (Muth, 1961). Moving beyond the temporal dimension, spatial econometric techniques have become prominent in capturing and quantifying spatial effects, often attributing causality through "spatial spillovers", and at the same time addressing econometric problems that otherwise result in biased coefficients and imprecise variance estimation (Anselin, 2010; LeSage and Pace, 2009). However, the introduction of spatial econometrics in Hedonic Pricing (HP) studies (e.g. Salvi, 2008; Cohen and Coughlin, 2008; Chalermpong, 2010; Andersson et al., 2010; Conway et al., 2010, Seo et al., 2014) has resulted in a quite common "temporal misspecification", where time-variant information about future prices is erroneously assumed to travel backwards in time.

This paper develops the use of a fundamental type of restriction to the spatial weight matrix $\mathbf{W}^{\mathrm{i}}$, the "arrow of time". The asymmetry (unidirectionality) of the temporal distance, as opposed to the symmetry (bidirectionality) of spatial distance, is an essential restriction to economic systems drawing its validity from the underlying physical systems. Causality in economics has to involve time, even if time is not explicitly included in the analysis, as is often the case with spatial models. Section 2.2 systematically reviews and classifies for the first time approaches that literally introduce "time into space" in a currently fragmented literature across fields with diverging terminology.

This literature employs a specific type of data ${ }^{\mathrm{ii}}$ comprised of individual observations each at a specific location and a specific moment/time-period, with no repetition. Henceforth, these data are referred to for brevity as "spatio-temporal" data ${ }^{\mathrm{iii}}$, as opposed to spatial panel data. The nature of this data necessitates the introduction of temporal restrictions to spatial interactions (see section 2.1 and 4.1). Alternative estimation strategies resort to spatial and/or temporal aggregation of spatio-temporal data to derive panel or cross-sectional data. These strategies result to loss of information, can cause the Modifiable Areal Unit Problem $(\mathrm{MAUP})^{\mathrm{iv}}$ and/or include implicit assumptions that require time-travel (see section 2.1). 
Further developing the "time into space" aspect, the paper proposes a novel methodological framework that combines the spatial and temporal dimensions to distinguish among and analyze different economic processes in the housing market. This framework not only specifies valid temporal restrictions to spatial interactions, but also captures information decay from events/sales not in (spatio-temporal) proximity, being discounted accordingly to spatio-temporal distance. This is particularly applicable to the HP method.

The temporal restrictions to spatial interactions distinguish between three distinct sources of influence on current prices. First, information on past prices affects current prices. There is a unidirectional link between past and current prices, or what is often cited as the "sales comparison" approach: a house price determination mechanism, in which the past prices of "comparable" properties affect prices of transactions in the present (Isakson, 2002; Des Rosiers et al., 2012; Small and Steimetz, 2012).

There is a significant challenge in finding appropriate information instruments for the effects of expectations on current prices/sales. Future prices are not appropriate instruments, as current expectations are only shaped by information in the present/past and not information from the future travelling back in time. Hence, the second source of influence on current house prices is future expectations encapsulated into sellers' asking price setting behavior of properties not yet sold. Essentially, this approach tests whether signals of sellers' expectations are captured in the asking prices houses not yet sold (see section 3.1), which are employed as instruments for market expectation effects. This is the first instance in the literature that effects other than the "own" asking price can be handled in model estimation.

As for the third source of influence on current house prices, it is hypothesized that distinct contemporaneous peer effects may be possible. These arise from the interaction between the different sellers, buyers and intermediaries within the narrow timeframe of active searching, competing and bargaining for the various (housing) options before concluding to a sale. There is a very limited timeframe, in which these peer effects can be truly contemporaneous, as by definition peer interactions might influence each final price, but the final prices themselves are not observable by the peers before each sale ${ }^{\mathrm{v}}$. Contrary to the observable past sale and asking prices, these peer interactions are not observed by the researcher. However, the researcher can observe the outcome of these contemporaneous peer interactions that is the 
prices of houses sold within the same timeframe. Therefore, the spatially weighted prices of houses sold within the same limited timeframe are employed as a proxy for these endogenous peer interactions.

The structure of this article is as follows. Section 2 provides the theoretical background of spatio-temporal HP models and comprehensively reviews the studies addressing the temporal misspecification in spatial HP models. Section 3 discusses market expectations and the role of the asking price. Section 4 describes the model selection process, specifies the spatiotemporal weights matrices, the spatio-temporal model and the estimation method. Section 5 illustrates the research context and presents an empirical case study. Section 6 discusses the modeling results, while the conclusions follow in Section 7.

\section{Hedonic Pricing, spatial econometrics and spatio-temporal data}

\subsection{The temporal dimension and spatial HP models}

The typical first-stage HP model in equation 1 expresses the sale price $y_{i t}$ of a house $i$ at time $t$ presented in a vector $\boldsymbol{y}$, as a function of the $k$ observable attributes $(k=1, \ldots, K)$ and a constant term in matrix $\mathbf{X}$, with $\boldsymbol{\beta}$ being a vector of parameters capturing the implicit prices of the individual characteristics and $\varepsilon$ is the error term.

$$
\boldsymbol{y}=\mathbf{X} \boldsymbol{\beta}+\varepsilon
$$

When HP model is applied to cross-section data, the subscript $t$ disappears, reflecting single "time-slice" of transactions. This is a common assumption even if transactions/data are recorded/observed at different times, with subscript $t$ having no impact on the specification. It is a common practice to account for time by introducing a set of "time" dummy variables in ordinary least square (OLS) estimation to control for the nominal aspect of price evolution as well as temporal heterogeneity (Wooldridge, 2000). Even if time dummy variables are introduced, imposing cross-sectional estimation to spatio-temporal data onerously assumes that all transactions take place simultaneously. This becomes particularly problematic when spatial econometric methods are employed through strictly spatial weight matrices where observations simultaneously influence each other. The strictly spatial specification looks for spatial spillovers effects in spatio-temporal data, but ignores the temporal dimension that is essential to identify the direction of such effects. 
In a HP framework for spatio-temporal data, prices ${ }^{\mathrm{vi}}$ are time-variant and information about future prices cannot possibly travel backwards in time. Hence, there are clearly no simultaneous decisions for extended periods of time, as is onerously specified by a typical strictly spatial weight matrix. Furthermore, future house prices cannot and should not be taken as proxies of current expectations for the future, as current expectations are only shaped by information in the present/past, amply demonstrated by the recent housing crisis. The temporal misspecification of $\mathbf{W}$ is quite common in recent spatial HP papers (e.g. Salvi, 2008; Cohen and Coughlin, 2008; Chalermpong, 2010; Andersson et al., 2010; Conway et al., 2010, Seo et al., 2014). The literature shows that the effect of misspecifying the temporal relations of spatio-temporal data can result in over-connected spatial weight matrices, which introduce serious biases to both testing for and the estimation of spatial autocorrelation models (Smith, 2009; Dubé and Legros, 2014). Dubé and Legros (2013a, 2013b, 2014), Smith and Wu (2009) and Thanos et al. $(2012,2015)$ stress the need to account for past observations affecting current observations in the spatial weights matrix $\mathbf{W}$, while dropping inappropriate assumptions of future observations influencing the present/past.

The approach in this paper takes account of both spatial and temporal dimensions without proceeding to any spatial aggregation ${ }^{\mathrm{vii}}$. Thus, the information on individual transactions can be exploited while taking into account the temporal dimension and avoiding MAUP or "arrow of time" violations. In the spatio-temporal specification, the $\boldsymbol{y}$ and $\boldsymbol{\varepsilon}$ vectors are of dimension $\left(N_{T} \times 1\right)$, while the matrix $\mathbf{X}$ is of dimension $\left(N_{T} \times(K+1)\right)$, where $N_{t}$ is the total number of individual spatial units collected in time period $t, T$ is the total number of time periods, and $N_{T}=\sum_{t=1}^{\mathrm{T}} N_{t}$.

The typical spatio-temporal data generating process (DGP) in the literature is illustrated by the simple extension of the spatial HP model to include a matrix $\mathbf{W}$ that expresses spatiotemporal relations instead of purely spatial. Thus, the classification of spatio-temporal models shown in Table 1 is derived by following the equivalent spatial econometrics classification (Halleck Vega and Elhorst, 2015). This list is not exhaustive, but serves as a classification to the model forms in the literature discussion below.

Table 1: Spatial and spatio-temporal models 


\begin{tabular}{|c|c|c|c|}
\hline Process & $\begin{array}{c}\text { Spatial: } \\
W=S\end{array}$ & $\begin{array}{c}\text { Spatio-temporal: } \\
\qquad \mathbf{W}=f(\mathbf{S}, \mathbf{T})\end{array}$ & Equation $^{\mathrm{a}}$ \\
\hline (y): Autoregressive (AR) & SAR & STAR & $\boldsymbol{y}=\rho \mathbf{W} \mathbf{y}+\mathbf{X} \boldsymbol{\beta}+\boldsymbol{\varepsilon}$ \\
\hline$(\boldsymbol{X})$ : Lag of x (LX) & SLX & STLX & $\boldsymbol{y}=\mathbf{X} \boldsymbol{\beta}+\mathbf{W X} \xi+\varepsilon$ \\
\hline$(\boldsymbol{y}, \boldsymbol{X})$ : Durbin Model (DM) & SDM & STDM & $\boldsymbol{y}=\rho \mathbf{W} \mathbf{y}+\mathbf{X} \boldsymbol{\beta}+\mathbf{W X} \xi+\boldsymbol{\varepsilon}$ \\
\hline$(\varepsilon)$ : Error Model (EM) & SEM & STEM & $\boldsymbol{y}=\mathbf{X} \boldsymbol{\beta}+\boldsymbol{u}, \boldsymbol{u}=\lambda \mathbf{W} \boldsymbol{u}+\boldsymbol{\varepsilon}$ \\
\hline $\begin{array}{l}(\boldsymbol{y}, \boldsymbol{X}, \boldsymbol{\varepsilon}) \text { : General nesting } \\
\text { model }(\mathrm{GN})\end{array}$ & GNS & GNST & $\begin{array}{c}\boldsymbol{y}=\rho \mathbf{W} \mathbf{y}+\mathbf{X} \boldsymbol{\beta}+\mathbf{W X} \xi+\boldsymbol{u} \\
\boldsymbol{u}=\lambda \mathbf{W} \boldsymbol{u}+\boldsymbol{\varepsilon}\end{array}$ \\
\hline
\end{tabular}

${ }^{a}$ where $\rho, \xi$ and $\lambda$ are scalar coefficients of the respective spatial or spatio-temporal effects; $\boldsymbol{u}$ is a spatio-temporally correlated error term.

\section{2. $\quad$ A systematic review of spatio-temporal HP applications}

Despite the significant proliferation of spatial econometrics, only a few papers have ever dealt with temporal misspecification in spatial weight matrices. Nevertheless, the number of such papers published in the last 5 years has doubled compared to the preceding decade, demonstrating a surge in the applicability and importance of spatio-temporal approaches. We counted 26 such papers, 8 in the real-estate literature, 9 in geography/regional science, 4 in statistics/econometrics and a couple each in transportation, forecasting and environmental economics literature. Table 2 presents a list of 21 spatio-temporal applications to the HP method.

Can and Megbolugbe (1997) were, to the authors' knowledge, the first HP paper identifying and correcting for the temporal misspecification. They ran STAR HP models with specifications of $\mathbf{W}$ that only included spatial effects from surrounding properties sold in the 6 months before the house sale. ${ }^{\text {vii }} \mathbf{W}$ is a lower triangular matrix when observations are ordered chronologically from earliest to latest. This specification accounts for past comparable sales' effect, but not an endogenous spatial spillover effect. They found significant spatial dependence effects, the exclusion of which, they argued, would influence the precision and accuracy of resulting price estimates. Brandt and Maennig (2011), who examined the influence of road noise on the prices of condominiums in Hamburg, follow the same approach diverging only in that prices of sales within the previous 12 months were included, instead of 6 months.

The seminal work of Pace et al. (1998) was the first to develop a specification of separate spatial $\mathbf{S}$, temporal $\mathbf{T}$ and spatiotemporal weights matrices, ST and TS. ${ }^{\text {ix }}$ The results show 
that the sales price of any property is strongly influenced by the sales prices of neighboring properties previously sold. They call their model STAR, even though the independent variables in $\boldsymbol{X}$ are also spatio-temporally weighted, which makes their specification an STDM. Many of the subsequent papers following this specification also call their models STAR. Nonetheless, for the sake of consistency and comparability, the reported models in Table 2 are characterized according to equations in Table 1 and not by their authors' own acronyms. Liu (2013) follows exactly the approach of Pace et al (1998) concluding that it fits the data best and produces better price forecasts than a simple OLS model for an enormous housing dataset in the Netherlands.

Pace et al. (2000) developed individual filter routines to the lower triangular matrices to maximize and take advantage of the high sparsity, ${ }^{x}$ avoiding lengthy determinant computations and making ML estimation feasible even with large datasets. Their findings show the spatio-temporal model with 14 variables outperforming not only the equivalent simple HP regression, but also a regression model that attempts to control for the all housing characteristics, including spatial and temporal effects with 211 variables.

Table 2: HP studies addressing the temporal dimension in spatio-temporal data

\begin{tabular}{|c|c|c|c|c|c|c|c|}
\hline Study & Market & City & $\begin{array}{l}\text { Study } \\
\text { Period }\end{array}$ & $\begin{array}{l}\text { Sample } \\
\text { Size }\end{array}$ & Model & $\begin{array}{c}\text { Estimation } \\
\text { method }\end{array}$ & $\begin{array}{l}\text { Weights } \\
\text { matrices }\end{array}$ \\
\hline $\begin{array}{l}\text { Can and Megbolugbe } \\
\text { (1997) }\end{array}$ & Residential & Miami (US) & 1990 & 944 & STAR & OLS & $\begin{array}{l}\text { Lower } \\
\text { triangular }\end{array}$ \\
\hline Pace et al. (1998) & Residential & $\begin{array}{l}\text { Virginia } \\
\text { (US) }\end{array}$ & $\begin{array}{l}1966- \\
1991\end{array}$ & 70,822 & STDM & OLS & $\begin{array}{c}\text { S, T, ST, } \\
\text { TS }\end{array}$ \\
\hline Pace et al. (2000) & Residential & $\begin{array}{l}\text { Baton Rouge } \\
\text { (US) }\end{array}$ & $\begin{array}{l}1984- \\
1992\end{array}$ & 5,243 & STDM & ML & $\begin{array}{c}\text { S, T, ST, } \\
\text { TS }\end{array}$ \\
\hline Tu et al. (2004) & Office & Singapore & $\begin{array}{l}1992- \\
2001 \\
\end{array}$ & 2,639 & STDM & Bayesian & $\begin{array}{c}\text { S, T, ST, } \\
\text { TS }\end{array}$ \\
\hline $\begin{array}{l}\text { Gelfand } \text { et al. } \\
(2003,2004)\end{array}$ & Residential & $\begin{array}{l}\text { Baton-Rouge } \\
\text { (US) }\end{array}$ & $\begin{array}{l}1985- \\
1995\end{array}$ & 1,327 & GNST & Bayesian & $\begin{array}{c}\text { S, T, ST, } \\
\text { TS }\end{array}$ \\
\hline Sun and Tu (2005) & Residential & Singapore & $\begin{array}{l}1990- \\
1999\end{array}$ & 54,282 & STDM & Bayesian & $\begin{array}{l}\text { S, T, ST, } \\
\text { TS }\end{array}$ \\
\hline Smith and Wu (2009) & Residential & $\begin{array}{l}\text { Philadelphia } \\
\text { (US) }\end{array}$ & $\begin{array}{l}2004- \\
2005\end{array}$ & 400 & $\begin{array}{l}\text { STAR, } \\
\text { STDM }\end{array}$ & ML & $\begin{array}{l}\text { Hadamard } \\
\quad(\mathbf{S} \circ \mathbf{T})\end{array}$ \\
\hline $\begin{array}{l}\text { Nappi-Choulet and } \\
\text { Maury (2009) }\end{array}$ & Office & $\begin{array}{l}\text { Paris } \\
\text { (France) }\end{array}$ & $\begin{array}{l}1991- \\
2005\end{array}$ & 2,516 & STDM & Bayesian & $\begin{array}{c}\text { S, T, ST, } \\
\text { TS }\end{array}$ \\
\hline $\begin{array}{l}\text { Beamonte et al. } \\
(2008,2010 \mathrm{a}, 2010 \mathrm{~b}, \\
2013)\end{array}$ & Residential & $\begin{array}{l}\text { Zaragoza } \\
\text { (Spain) }\end{array}$ & $\begin{array}{l}2002- \\
2004\end{array}$ & 788 & STDM & Bayesian & $\begin{array}{l}\text { S, T, ST, } \\
\text { TS }\end{array}$ \\
\hline
\end{tabular}




\begin{tabular}{|c|c|c|c|c|c|c|c|}
\hline Alberto et al. (2010) & Residential & $\begin{array}{l}\text { Zaragoza } \\
\text { (Spain) }\end{array}$ & $\begin{array}{l}2002- \\
2004\end{array}$ & 788 & STDM & Bayesian & $\begin{array}{l}\mathbf{S}, \mathbf{T}, \mathbf{S T}, \\
\mathbf{T S}\end{array}$ \\
\hline $\begin{array}{l}\text { Nappi-Choulet and } \\
\text { Maury (2011) }\end{array}$ & Residential & $\begin{array}{l}\text { Paris } \\
\text { (France) }\end{array}$ & $\begin{array}{l}1991- \\
2005\end{array}$ & 220,418 & STDM & ML & $\begin{array}{l}\text { S, T, ST, } \\
\text { TS }\end{array}$ \\
\hline $\begin{array}{l}\text { Brandt and Maenig } \\
\text { (2011) }\end{array}$ & Residential & $\begin{array}{l}\text { Hambourg } \\
\text { (Germany) }\end{array}$ & $\begin{array}{l}2002- \\
2008\end{array}$ & 4,832 & STAR & ML & $\begin{array}{l}\text { Lower } \\
\text { triangular }\end{array}$ \\
\hline Thanos et al. (2012) & Residential & $\begin{array}{l}\text { Athens } \\
\text { (Greece) }\end{array}$ & $\begin{array}{l}1996- \\
2001\end{array}$ & 1,613 & STEM & ML & $\begin{array}{l}\text { Hadamard } \\
(\mathbf{S} \circ \mathbf{T})\end{array}$ \\
\hline Thanos et al. (2015) & Residential & $\begin{array}{l}\text { Athens } \\
\text { (Greece) }\end{array}$ & $\begin{array}{l}2001- \\
2003\end{array}$ & 773 & STEM & ML & $\begin{array}{l}\text { Hadamard } \\
(\mathbf{S} \circ \mathbf{T})\end{array}$ \\
\hline $\begin{array}{l}\text { Dubé and Legros } \\
\text { (2013b) }\end{array}$ & Residential & $\begin{array}{l}\text { Lucas } \\
\text { County (US) }\end{array}$ & $\begin{array}{l}1993- \\
1998\end{array}$ & 25,357 & $\begin{array}{l}\text { STAR, } \\
\text { STEM }\end{array}$ & OLS/ML & $\begin{array}{l}\text { Hadamard } \\
\quad(\mathbf{S} \circ \mathbf{T})\end{array}$ \\
\hline $\begin{array}{l}\text { Dubé and Legros } \\
\text { (2014) }\end{array}$ & Residential & $\begin{array}{l}\text { Paris } \\
\text { (France) }\end{array}$ & $\begin{array}{l}1990- \\
2001\end{array}$ & 127,787 & STAR & OLS/ML & $\begin{array}{l}\text { Hadamard } \\
(\mathbf{S} \circ \mathbf{T})\end{array}$ \\
\hline Liu (2013) & Residential & $\begin{array}{l}\text { Randstad } \\
\text { (Netherlands) }\end{array}$ & $\begin{array}{l}1997- \\
2007\end{array}$ & 437,734 & STDM & OLS & $\begin{array}{c}\text { S, T, ST, } \\
\text { TS }\end{array}$ \\
\hline
\end{tabular}

Gelfand et al. (1998) developed a Bayesian approach to conditional autoregressive models that provides the flexibility to deal with spatial and temporal effects. This was employed by Gelfand et al. (2003, 2004) to incorporate spatial information when explaining the temporal evolution of house prices. They developed a GNST specification containing spatial and temporal autocorrelation with time-varying parameters. Gelfand et al. (2004) is an extension of the spatially varying coefficients approach presented in Gelfand et al. (2003) to incorporate repeated house sales and a hierarchical approach to modeling.

Sun et al. (2005) also developed a Bayesian estimation approach for a two order autoregressive STDM. They argued that their approach produces more robust coefficients by efficiently detecting and correcting heteroskedasticity compared to OLS. However, they do find a trade-off between the heteroskedastic robustness and the incorporation of spatial information into the model estimation. Nevertheless, they contend that it is more efficient to derive location and building specific indices by specifying a two order autocorrelation in an STDM, since price movements may not be identical in different development locations and at different times. Following a similar specification, Tu et al. (2004) is the first spatio-temporal hedonic model applied to the office market, constructing transaction-based office price indexes at the building level.

Along the same lines, Beamonte et al. (2008, 2010a, 2010b, 2013) and Alberto et al. (2010) also employ Bayesian linear regressions, addressing heteroskedasticity problems, to estimate 
STDMs applied to the same dataset from the residential market of Zaragoza, Spain. Beamonte et al. (2013) produce a constant quality housing index. Alberto et al. (2010) developed a "multicriteria" methodology for variable selection and spatio-temporal effects in hedonic models. A genetic algorithm is proposed for identifying Pareto efficient solutions to solve the multi-objective problem. They make out-sample predictions which they argue better reflect the uncertainty associated with the selection and estimation processes in HP.

Nappi-Choulet and Maury (2009) apply a version of the Bayesian STDM model to the Paris office market and test for temporal heterogeneity. They specify and test for a structural break at a specific date that is endogenously determined. They find both spatial and temporal effects to be significant and the size of spatial and temporal dependence coefficients differ widely according to the transaction date. They also show the presence of temporal heterogeneity in the Paris office market. Nappi-Choulet and Maury (2011) propose a full endogenous treatment of spatial and temporal heterogeneity. They select spatially and temporally consistent data sub-samples and estimate an HP model from these sub-samples. The sub-sample selection for each house sale price is compiled by taking a pre-specified number of closest temporal and then spatial neighbors. They find evidence of strong spatial and temporal heterogeneity. First, the spatial autoregressive effects seem to be greater in the historical centre of Paris than in some parts of the surrounding districts. Secondly, the marginal price of some positive housing attributes is lower in housing booms than busts.

Smith and Wu (2009) developed a STAR specification with temporally auto-correlated residuals. Their weights matrix is a Hadamard product between spatial and temporal distance weight matrices $\left(\mathbf{W}=\mathbf{S} \odot \mathbf{T}=\left[\mathbf{s}_{\mathbf{i j}}\right] \times\left[\boldsymbol{t}_{\boldsymbol{i j}}\right]\right)$ that identifies the spatiotemporal neighbours that affect price determination. They also note that the separate spatiotemporal terms ST and TS in the specification of Pace et al. (1998, 2000) are compound effects, which are necessarily indirect.

Thanos et al. $(2012,2015)$ specified both a lower triangular matrix and a Hadamard spatiotemporal matrix with time decay, comparing them to the typical temporally misspecified $\mathbf{W}$. As guidance for model selection, they employed robust Lagrange multiplier (LM) tests. They found that LM tests of misspecified $\mathbf{W}$ were inconclusive, showing both SAR and SEM as statistically significant, whereas the spatio-temporal weights only showed STEM as 
significant. This could reflect newly built houses being a big part of their data, suggesting it was the unobserved effects from introducing new houses and improvements in the urban structure that influenced future prices rather than past house prices. They also found that ignoring the temporal dimension of housing spatio-temporal data leads to the underestimation of environmental disamenities, possibly due to overestimation of spatial dependence.

Dubé et al., (2011) propose a general way of capturing the spatial effects while accounting for the temporal dimension. Based on discrete time period specification, a general spatiotemporal weights matrix can be constructed to isolate multidirectional spatial effects. Dubé and Legros (2013a) evaluate the strength of spatial dependence in OLS residuals and fund that ignoring the temporal dimension can lead to misinterpretation of actual spatial dependence. Dubé and Legros, (2013b) propose the use of Hadamard spatio-temporal matrices to distinguish the unidirectional temporal effect of past to future sales prices and the simultaneous endogenous effect between prices in the same period. They use STEM and STAR specifications and find that both effects are statistically significant. They also caution that mechanical spatial applications implicitly make many strong, and potentially wrong, assumptions.

Smith (2009) provides a theoretical exposition of the over-connection problem when all observations are assumed to be simultaneously interconnected in strictly spatial $\mathbf{W}$. This issue is typically addressed by a distance cut-off point for spatial effects. Dubé and Legros (2014) test a range of distance cut-off points between $0.5 \mathrm{~km}$ and $3 \mathrm{~km}$, recovering severe overconnection bias at higher cut-off points in SAR. This is indicated by spatial autoregressive coefficients near unity, negative constants, and unstable coefficients. A correctly specified STAR reduces the magnitude of the autoregressive coefficients by a factor of 3.5 at the $0.5 \mathrm{~km}$ cut-off to a factor of 10 at $3 \mathrm{~km}$, removing much of the over-connection bias that was there due to the temporal misspecification. Out-of-sample estimation shows SAR to underperform STAR in all cases and OLS in all but the $1.5 \mathrm{~km}$ cut-off point.

The spatio-temporal application can also be extended to a class of models called Geographical Weighted Regression (GWR) that produces spatially weighted distributions of locally varying coefficients for $\mathbf{X}$, not the typical global parameters for spatial effects. Huang et al. (2010) develop Geographical and Temporally Weighted Regressions (GTWR) that deal 
with both spatial and temporal non-stationarity simultaneously. They specify a weighting system based on a Hadamard product between a spatial and a temporal weight matrix. Their results show GTWR yielding $46.4 \%$ and $15.6 \%$ improvements in model fitting over OLS and GWR respectively. A similar approach was followed by Wrenn and Sam (2014), who noted that time, unlike space, is one-directional, so, intuitively, it may seem that smoothing time both forward and backwards using the two-sided kernel does not make sense. However, they went on to report only the results the two-sided kernel models, citing that this approach provides better performance. This illustrates the problem of consistently removing erroneous assumptions with regard to the temporal dimension, even in cases where the misspecification have been noted by the researchers.

As seen in this section, a significant part of the literature opts for the Bayesian approach to correct for heteroskedasticity, whereas ML estimation is employed when endogenous effects are specified. Some recent approaches forgo the influential spatio-temporal matrix specification of Pace et al $(1998,2000)$ for a Hadamard product. Section 4.1 demonstrates which of these two the spatio-temporal matrix approaches best explain the economic processes at work in the housing market. Section 4.1 also argues for the use of STAR in this context, despite the prevalence in Table 2 of STDM, again due to the influence of the seminal Pace et al $(1998,2000)$ paper.

\section{Market expectations: the role of the asking price}

The asking price setting behavior of the seller can potentially influence final sale prices. The seminal paper of Tversky and Kahneman (1974) puts the concepts of heuristics and anchoring at the centre of academic debate. Heuristics are cognitive short cuts that simplify decision making. Anchoring is when a value estimate is disproportionately influenced by an initial reference value or an anchor and any adjustments from the anchor are underweighted, resulting in bias. One of the first studies to apply these concepts to the housing market was Black and Diaz III (1996), who conducted bilateral negotiation experiments on the effect of asking price on the final price and found it significant. They attribute this to negotiators devaluing cognitively-demanding processes in favor of heuristics. They provide evidence that even when the asking price was incongruous, negotiators may anchor on it and devalue cognitively-demanding property-specific and market information. They argue that asking- 
price anchors not only influence settlement prices, but also have a stabilizing impact. Diaz III et al. (1999) report consistent findings in a similar experiment with the addition of incentives for good performance.

Scott and Lizieri (2012) conducted consumer choice experiments with 139 students to simulate first-time house buyers. Even in the presence of incentives for accurate appraisal, they find that individuals rely on arbitrarily established anchor values. The initial anchors remain powerful enough to influence subsequent valuations. They argue that there is a strong tendency to use an anchoring-and-adjustment mechanism as a rule of thumb to make value judgments in housing, especially since it is relatively easy to establish anchors and once they become established in one's perceptions, biased anchors may exert a lasting influence.

Moving from the buyer's perspective to seller's asking price setting behavior, Yavas and Yang (1995) note that sellers may use asking prices to convey private information, as strategic signals, to specific buyers. Hui and $\mathrm{Yu}$ (2012) find that the effectiveness of raising list prices, in optimizing sellers' returns, depends on economic conditions as well as on market expectations as to future property prices.

Haurin et al. (2013) employ a two stage HP model on data from Belfast. Their results show that sellers set asking prices based on their expectations of future changes in sales prices and the arrival rate of buyers. They find support for the conjecture that sellers switch to an auction-like model during housing booms. They also find asking prices to be "sticky" in deflating market conditions.

Unlike the US and elsewhere in the UK, the vast majority of houses in Scotland are sold through an officially established "auction-like model" similar to what Haurin et al. (2013) allude to. The sale mechanism is a "first-price sealed-bid" auction over the asking price. Thanos and White (2014) employ an Instrumental Variables approach to model the difference between selling and asking price or "bid-premium" as they called it, employing data from Aberdeen. Their results are consistent with a theoretical framework, where a seller sets an asking price that maximizes her expected value of the bid-premium. This bid-premium is affected endogenously by the asking price itself and exogenously by the number of participants in the auction and the time on the market. There is a balancing act of positive 
anchoring effects or signaling premium quality from setting a higher asking price, while maximizing auction participant numbers and minimizing time on the market by setting the lowest asking price possible. They find that sellers' inclination in this balancing act depends heavily on market conditions and expectations of future price movements. They do agree with Haurin et al. (2013) about the stickiness of asking prices at the onset of an economic downturn, which they partly attribute to lagged information available to sellers when asking prices are being set.

The relevant points from this brief review are that asking price setting reflects sellers' expectations about the future direction of prices, which are not necessarily correct. Nevertheless, due to strategic behavior and anchoring, asking prices can be expected to affect final sale prices. In fact, there are a few studies, as discussed below, that address the asking price in a HP framework, but none can deal with the effects beyond the own asking price of a sale.

\section{Specifying spatio-temporal HP models}

The methodological challenge here is to adapt the HP model to explicitly test the three hypotheses of distinct economic processes at work: "comparable sales", "sellers' expectations" and "contemporaneous spatial peer" effects.

\subsection{A spatio-temporal data generating process for HP models}

Kuminoff and Jarrah (2010) argue that if spatially delineated amenities are conveyed through the location of a house, it seems reasonable to assume that households will perceive each house as being unique. This argument can be extended to include the temporal dimension, where constant shifts in market conditions and household preferences make house prices time-variant. These prices are reached by local equilibria between supply and demand of housing attribute bundles at specific times and locations. In the comparable sales paradigm, the buyer is influenced by other sales in temporal and spatial proximity that provide information on how non-identical bundles of housing attributes are capitalized in the market. Hence, sales with the maximum available proximity in time and space are sought by the market participants as information sources for the equilibrium between housing supply and demand that changes across time and space. Information from sales not as proximal is 
discounted accordingly to spatio-temporal distance. The hedonic price of each house is analyzed here through the available information to buyers up to the time of the sale.

The question then becomes what are the a priori expectations for the "true" DGP, which are explicitly illustrated here. First, except from the detailed information of all observable attributes $\boldsymbol{x}_{i k}$ of house $i$ about to be purchased at time $t$, the buyer is exposed to information about the past sale price $y_{j(t-p)}$ of house $j$ in time period $t-p$. The effects from a past sale $y_{j(t-p)}$ are unidirectional and can include pecuniary and technological spillovers. Second, information about the asking price $y_{m(t+q)}^{*}$ of house $m$ that has come on to the market and has not yet been sold, but will be sold at $t+q$, is also available potentially affecting the price $y_{i t}$. Third, the buyer may interact and compete with other buyers and sellers directly or through agents and auctions within the very limited time period typically contingent to market specific sale procedures and mechanisms. The price $y_{h t}$ of spatial neighbor $h$ is a proxy for this interaction. This is specified as a short-term endogenous effect that has a strong pecuniary aspect, but can also capture short term reactions to technological shocks, if these are prominent in the data.

These three price information effects signify an autoregressive ${ }^{\mathrm{xi}}$ model form, resulting to the STAR model in Equation 2:

$$
y_{i t}=\alpha+\psi \sum_{j=1}^{J} w_{i j} y_{j(t-p)}+\varphi \sum_{m=1}^{M} w_{i m} y_{m(t+q)}^{*}+\rho \sum_{h=1}^{H} w_{i h} y_{h t}+\sum_{k=1}^{K} \beta_{k} x_{i k t}+\varepsilon_{i t}
$$

where the parameters $\psi, \varphi$, and $\rho$ represent the "comparable sales", the "sellers' expectations", and "contemporaneous peer" effects respectively. The issue of correctly combining temporal and spatial distances, is an empirical question (Huang et al., 2010). Given the different measurement unit constraint, temporal distance is treated as a time decay function that multiplies a function of the spatial distance. Hence, the spatio-temporal distance $w_{i j}$ between observations $i$ and $j$ can be given by the product of the function spatial distance $d_{i j}$ multiplied by a function of the temporal distance $\tau_{i j}$ in equation 3 :

$$
\mathrm{w}_{\mathrm{ij}}=f\left(d_{i j}\right) \times f\left(\tau_{i j}\right)
$$

This suggests that a Hadamard product and not a simple matrix multiplication, as in the specification of Pace et al $(1998,2000)^{x i i}$, would be the appropriate way of combining spatial and temporal distance matrices in a single spatio-temporal matrix. 


\subsection{Building the Spatio-temporal Weights Matrices}

Having specified a generalization of the HP method to a STAR model and a Hadamard matrical product, the following details operationalize the process of constructing the spatiotemporal matrices. First, the data are chronologically ordered. Second, time period $t$ is assumed here to be discrete, which considerably simplifies exposition without any loss of generality given the different number of observations for each time period $\left(N_{1} \neq N_{2} \neq\right.$ $\cdots N_{R}$ ). This is not a necessary condition, the specification can be easily adopted to continuous time.

The spatial link between observations $i$ and $j, s_{\mathrm{ij}}$, represents the strength of the spatial connection that is typically a function of Euclidian distance $d_{i j}$ (equation 4).

$$
\mathrm{s}_{\mathrm{ij}}=\left\{\begin{array}{c}
e^{-d_{i j}} \text { if } i \neq j \text { and } d_{i j} \leq d_{c} \\
0 \quad \text { if } i=j \text { or } d_{i j}>d_{c}
\end{array}\right.
$$

Where $d_{c}$ represents a cut-off distance that is selected by the researcher and can be equal for all observations or unique for each observation. A single cut-off distance is problematic with regard to dwelling density: in dense neighborhoods there are many interconnected observations; and in sparsely populated areas some observations are left with no neighbors. Therefore, we specify the cut-off distance to be the mean distance for each observation $\left(d_{c}=\bar{d}_{i}\right)$. The distance between two points is also not taken as a linear effect but a nonlinear dissipation of the spatial connection is introduced. This allows even a misspecified spatial econometric model to forgo the problems of over-connectivity shown by Smith (2009) and tested by Dubé and Legros (2014). Pooling all the elements $s_{i j}$ into a single matrix produces the $\left(N_{T} \times N_{T}\right)$ spatial weights matrix $\mathbf{S}$ in equation 5 , typically employed in strictly spatial econometric models.

$$
\mathbf{S}=\left[\begin{array}{ccccc}
0 & \mathrm{~s}_{12} & \mathrm{~s}_{13} & \cdots & \mathrm{s}_{1 \mathrm{~N}_{\mathrm{R}}} \\
\mathrm{s}_{21} & 0 & \mathrm{~s}_{23} & \cdots & \mathrm{s}_{2 \mathrm{~N}_{\mathrm{R}}} \\
\mathrm{s}_{31} & \mathrm{~s}_{32} & 0 & \cdots & \mathrm{s}_{3 \mathrm{~N}_{\mathrm{R}}} \\
\vdots & \vdots & \vdots & \ddots & \vdots \\
\mathrm{s}_{\mathrm{N}_{\mathrm{R}} 1} & \mathrm{~s}_{\mathrm{N}_{\mathrm{R}} 2} & \mathrm{~s}_{\mathrm{N}_{\mathrm{R}} 3} & \cdots & 0
\end{array}\right]
$$

This symmetric spatial weight matrix can also be expressed as the composition of spatial matrices connecting observations within and between discrete time periods $R$ in equation 6 . 


$$
\mathbf{S}=\left[\begin{array}{ccccc}
\mathbf{S}_{11} & \mathbf{S}_{12} & \mathbf{S}_{13} & \cdots & \mathbf{S}_{1 \mathrm{R}} \\
\mathbf{S}_{21} & \mathbf{S}_{22} & \mathbf{S}_{23} & \cdots & \mathbf{S}_{2 \mathrm{R}} \\
\mathbf{S}_{31} & \mathbf{S}_{32} & \mathbf{S}_{33} & \cdots & \mathbf{S}_{3 R} \\
\vdots & \vdots & \vdots & \ddots & \vdots \\
\mathbf{S}_{\mathrm{R} 1} & \mathbf{S}_{\mathrm{R} 2} & \mathbf{S}_{\mathrm{R} 3} & \cdots & \mathbf{S}_{\mathrm{RR}}
\end{array}\right]
$$

Where, for example, $\mathbf{S}_{\mathbf{1 1}}$ expresses the spatial connection among the transactions occurring in the first time period, and so on for all $\mathbf{S}_{\mathbf{R R}}$ matrices. Using this notation, $\mathbf{S}$ can be decomposed into block-diagonal, lower triangular and upper triangular matrices. For spatio-temporal data, the elements on the main block diagonal represent the spatial relations among contemporaneous observations. The lower triangular matrix indicates the spatial connection between observations occurring in $t-p$ to the observations occurring in time period $t$ (past to present). The upper triangular matrix indicates the connections between observations occurring in time period $t+q$ to the observations occurring in time period $t$ (future to present).

A temporal weights matrix, $\mathbf{T}$, can be expressed in similar way, by calculating the temporal distance, $\tau_{i j}$ in equation 7 , between an observation $i$ collected in a given time period $t_{i}$ and observation $j$ collected in time period $t_{j}$.

$$
\tau_{i j}= \begin{cases}\left(t_{i}-t_{j}\right)^{-1} & \forall t_{i} \neq t_{j} \\ 1 & \forall t_{i}=t_{j}\end{cases}
$$

Following the approach in equation 6, temporal distances $\tau_{i j}$ are included as the compilation of matrices for discrete time periods $R$ that make up the $\left(N_{T} \times N_{T}\right)$ matrix $\mathbf{T}$ in equation 8 .

$$
\mathbf{T}=\left[\begin{array}{ccccc}
\mathbf{T}_{11} & -\mathbf{T}_{12} & -\mathbf{T}_{13} & \cdots & -\mathbf{T}_{1 \mathrm{R}} \\
\mathbf{T}_{21} & \mathbf{T}_{22} & -\mathbf{T}_{23} & \cdots & -\mathbf{T}_{2 \mathrm{R}} \\
\mathbf{T}_{31} & \mathbf{T}_{32} & \mathbf{T}_{33} & \cdots & -\mathbf{T}_{3 R} \\
\vdots & \vdots & \vdots & \ddots & \vdots \\
\mathbf{T}_{\mathbf{R} 1} & \mathbf{T}_{\mathbf{R} 2} & \mathbf{T}_{\mathbf{R} 3} & \cdots & \mathbf{T}_{\mathbf{R R}}
\end{array}\right]
$$

$\mathbf{T}$ is markedly different to $\mathbf{S}$ in that its upper triangle is negative, as spatial distance between two points is symmetric while temporal distance is not, hence the arrow of time. $\mathbf{T}$ can be further decomposed to test the first and second hypotheses in section 1 . The first hypothesis that past sales prices affect current prices is captured by $\underline{\mathbf{T}}$ in equation 9 .

$$
\underline{\mathbf{T}}=\left[\begin{array}{ccccc}
\mathbf{0} & \mathbf{0} & \mathbf{0} & \cdots & \mathbf{0} \\
\mathbf{T}_{21} & \mathbf{0} & \mathbf{0} & \cdots & \mathbf{0} \\
\mathbf{T}_{31} & \mathbf{T}_{32} & \mathbf{0} & \cdots & \mathbf{0} \\
\vdots & \vdots & \vdots & \ddots & \vdots \\
\mathbf{T}_{\mathbf{R} 1} & \mathbf{T}_{\mathbf{R} 2} & \mathbf{T}_{\mathbf{R} 3} & \cdots & \mathbf{0}
\end{array}\right]
$$


The second hypothesis, that there is a contemporaneous peer effect within a very limited period before the sale, which is captured in $\ddot{\mathbf{T}}$ (equation 10).

$$
\ddot{\mathbf{T}}=\left[\begin{array}{ccccc}
\mathbf{T}_{11} & \mathbf{0} & \mathbf{0} & \cdots & \mathbf{0} \\
\mathbf{0} & \mathbf{T}_{22} & \mathbf{0} & \cdots & \mathbf{0} \\
\mathbf{0} & \mathbf{0} & \mathbf{T}_{33} & \cdots & \mathbf{0} \\
\vdots & \vdots & \vdots & \ddots & \vdots \\
\mathbf{0} & \mathbf{0} & \mathbf{0} & \cdots & \mathbf{T}_{\mathbf{R R}}
\end{array}\right]
$$

Where all the non-zero elements are set to one, denoting that all relationships within $\ddot{\mathbf{T}}$ are contemporaneous and the respective spatial weights would not be subjected to time-decay.

The temporal distance $\tau_{i j}^{*}$, between the sale time $t_{i}$ of house $i$ and the time $t_{j}^{*}$ that house $j$ was put in the market, is calculated in equation 11. This explicitly includes only effects from other houses that are in the market but have not yet been sold, addressing the problem of having negative temporal distances in the upper triangle of the matrix. Hence, it is now possible to test the third hypothesis: the asking prices of houses not yet sold operate as signals of sellers' expectations, influencing buyers' behavior and final sales prices.

$$
\tau_{i j}^{*}=\left\{\begin{array}{c}
\left(t_{i}-t_{j}^{*}\right)^{-1} \forall t_{i} \neq t_{j}^{*} \wedge t_{j}>t_{i}>t^{*} \\
0 \quad \text { otherwise }
\end{array}\right.
$$

When the data are ordered chronologically this produces in equation 12 a non-negative upper triangular matrix $\overline{\mathbf{T}}$.

$$
\overline{\mathbf{T}}=\left[\begin{array}{ccccc}
\mathbf{0} & \mathbf{T}_{12}^{*} & \mathbf{T}_{13}^{*} & \cdots & \mathbf{T}_{1 R}^{*} \\
\mathbf{0} & \mathbf{0} & \mathbf{T}_{23}^{*} & \cdots & \mathbf{T}_{2 R}^{*} \\
\mathbf{0} & \mathbf{0} & \mathbf{0} & \cdots & \mathbf{T}_{3 R}^{*} \\
\vdots & \vdots & \vdots & \ddots & \vdots \\
\mathbf{0} & \mathbf{0} & \mathbf{0} & \cdots & \mathbf{0}
\end{array}\right]
$$

It now is relatively straight-forward to combine temporal and spatial distances (weights) by taking the Hadamard product between the spatial matrix $\mathbf{S}$ and each of the temporal matrices $\overline{\mathbf{T}}, \ddot{\mathbf{T}}$ and $\underline{\mathbf{T}}$ in equations 13 to 15 . This set of spatio-temporal matrices allows for the testing of the three research hypotheses specified in section 1.

$$
\begin{gathered}
\underline{\mathbf{W}}=\mathbf{S} \odot \underline{\mathbf{T}} \text { (comparable past sales effect) } \\
\ddot{\mathbf{W}}=\mathbf{S} \odot \ddot{\mathbf{T}} \text { (contemporaneous peer effect) } \\
\overline{\mathbf{W}}=\mathbf{S} \odot \overline{\mathbf{T}} \text { (sellers' expectations effect) }
\end{gathered}
$$


$\ddot{\mathbf{W}}, \underline{\mathbf{W}}$, and $\overline{\mathbf{W}}$, can be row-standardized to simplify the interpretation of the effects. The inclusion of the temporal dimension highly contributes to sparsity ${ }^{x i i}$ of these matrices, further addressing the problem of over-connectivity bias (Dubé and Legros, 2014; Smith, 2009). Moreover, the pitfall of multiple weight matrices in a single equation model described by LeSage (2014) does not apply in this case, as the temporal restrictions to the spatial interactions do not allow the matrices to overlap in space-time. Hence, there can be no covariance between the three matrices that would have otherwise required the specification of extra interaction terms restricting the identification and the interpretation of direct and indirect effects from the different matrices.

\subsection{STAR specification and estimation method}

The complete structural form of STAR model can now be expressed in equation 16 by introducing the spatio-temporal weight matrices (equations 13 to 15) to equation 2.

$$
\mathbf{y}=\rho \ddot{\mathbf{W}} \mathbf{y}+\psi \underline{\mathbf{W}} \mathbf{y}+\varphi \overline{\mathbf{W}} \mathbf{y}^{*}+\mathbf{X} \beta+\boldsymbol{\varepsilon}
$$

The reduced form of STAR model is given in equation 17:

$$
\mathbf{y}=[\mathbf{I}-\rho \ddot{\mathbf{W}}-\psi \underline{\mathbf{W}}]^{-1} \times\left[\varphi \overline{\mathbf{W}} \mathbf{y}^{*}+\mathbf{X} \beta+\boldsymbol{\varepsilon}\right]
$$

where I is the identity matrix of dimensions $\left(N_{T} \times N_{T}\right)$. Before the STAR model can be estimated using the standard maximum likelihood procedure, it is first necessary to ensure that the matrix $(\mathbf{I}-\rho \ddot{\mathbf{W}}-\psi \underline{\mathbf{W}})$ has a defined inverse, or is of full rank (LeSage and Pace, 2009). This is the case if and only if this matrix can be transformed to full rank, given that $\underline{\mathbf{W}}$ and $\overline{\mathbf{W}}$ separately are not of full rank. The first $\mathrm{N}_{1}$ elements of $\underline{\mathbf{W}}$ are necessarily equal zero, since the first block row of the matrix does not depict any past transactions. Similarly, the $\overline{\mathbf{W}}$ matrix has the last $N_{R}$ elements equal to zero. It is necessary to drop a few observations in the first and the last time-periods to avoid introducing bias in the estimation of $\psi$ and $\varphi$ by including "false zeros" in the estimation process (Dubé et al., 2014). This transformation can be seen as the spatio-temporal "equivalent" of the Cochrane-Orcutt. Thereafter, the ML estimation can be applied, since the row-standardized weight matrix now of dimensions $\left[\left(N_{T}-\left(N_{1}+N_{R}\right)\right) \times\left(N_{T}-\left(N_{1}+N_{R}\right)\right)\right]$ is of full $\operatorname{rank}^{\mathrm{xiv}}$. The form of the hedonic price function is not strictly prescribed by economic theory. A semi-log specification is selected, as it is the most widely used in the literature and provides an excellent goodness-of-fit to our data. 
It is noted that only the coefficient $\varphi$ can be interpreted as an elasticity, due to the semi-log specification and to the fact that the variable is strictly exogenous and pecuniary in nature. $\psi$ is the dynamic effect of a shock in the prices at a given time, propagating to the next period. The sequence of past influences that replicate over subsequent time periods provide a technological long-run effect, which is obtained by multiplying the appropriate $\beta$ by the temporal multiplier $1 /(1-\psi)$. As mentioned in section 4.1 , the contemporaneous peer effect $\rho$ may include technological effects in some cases. In such a case, the corresponding $\beta$ coefficient measures the direct effect, while the total effect is obtained by multiplying $\beta$ with the multiplier $1 /(1-\rho)$. If $\rho$ is strictly a pecuniary then $\beta$ coefficient captures the total direct effect, not requiring spatial multiplier (Small and Steimetz, 2012).

\section{Research Context and Data}

\subsection{The Scottish housing auction system and its implications for modeling}

The data used in this study are from Aberdeen in the north east of Scotland and were provided by Aberdeen Solicitors Property Centre. The sealed-bid auction is the dominant mechanism in Scotland (Thanos and White, 2014). Auction participants submit a bid on the basis of a professional valuation and an "offers-over" asking price set by the seller (Pryce and Gibb 2006), which is not legally binding. The asking price is set by the vendor in consultation with her real estate agent. The "offers-over" asking price in the Scottish system is different to systems in England and the US, where many houses are sold below their asking prices, in which circumstances it is possible to see the asking price as a ceiling price.

The seller is not required to set a closing date and can enter into private negotiations with the first interested party (Thanos and White, 2014). The "private treaty" or "fixed price" selling mechanism can also be adopted at the start of the marketing process (Pryce, 2011). Unlike the open outcry auction, the date of a sealed bid auction in Scotland is not pre-set. It is only set when the seller's solicitor receives two or more "notes of interest" (Pryce and Gibb 2006; Pryce 2011). The bids are revealed to the seller after the "closing date" for offers has elapsed. At the time of bid submission, the potential buyers do not know the number of auction participants, but they are aware of the number of "notes of interest". 
The above show that there is significant interactions between market participants through sale mechanism selection and the auction process. There is also a substantial lag between the auction date and the conclusion of the sale (signing of contracts) after which final price information can be accessed by other market participants and affect sales in the future. The whole process can take about a month, which is taken as time $t$ in the model estimation, signifying that $\ddot{\mathbf{W}}$ captures the contemporaneous peer effect within a month before the sale, when maximum interaction between market participants is expected and final price information is not observed by other participants. The $\underline{\mathbf{W}}$ matrix captures the past comparable sales effect based on all sold over a month ago $\left(t_{i}-t_{j} \geq 1\right)$.

In our data, $90 \%$ of the houses are sold within 93 days of being put in the market, which is consistent with the literature (Pryce and Gibb, 2006; Zuehlke, 1987). Therefore, $\overline{\mathbf{W}}$ matrix is based only on asking prices of houses put on the market within a quarter of the sale, but not sold yet $\left(t_{i}-t_{j}^{*} \leq 3\right.$ and $\left.t_{i}-t_{j}<0\right)$. This specification includes the vast majority of observations and at the same time drops asking prices that have been set too far back to reflect current market expectations or are outlier observations.

\subsection{Data description}

The dataset contains information on asking and selling prices, structural characteristics of the property, location, and duration on the market. GIS was used to derive spatial variables such as distance to the central train station and the airport, the dominant type of housing and dwelling density. A range of socioeconomic characteristics for each neighborhood were also introduced, such as the proportion of people living alone, over 60 years and with no formal qualifications, and the percentage of households having two or more cars. Table 3 provides the variable list and the descriptive statistics.

Figure 1 illustrates the spatio-temporal distribution of the data. A few transactions occur at the beginning and at the end of the sample. There is also a clear seasonal pattern that is captured through quarterly dummy variables. The distribution of the number of houses put on the market is similar to the distribution of the sales. However, most properties are put on the market between March and August and sales peak a couple of months later; a lead consistent with the sale process described above. Figure 2 shows the inflationary conditions in the Aberdeen housing market between 2004 and 2007. 
The initial dataset contained 18,867 transactions where all the information on the variables are available across the city of Aberdeen from 2004 to 2007. The observations in the first and last two months are excluded from the analysis to ensure that the weight matrices are of full rank, as discussed in section 4.3. Hence, 17,830 observations are used in the model estimation process. It is stressed that the excluded data was employed for building $\underline{\mathbf{W}} \mathbf{y}$ and $\overline{\mathbf{W}} \mathbf{y}^{*}$.

Table 3: Descriptive statistics of the data

\begin{tabular}{|c|c|c|c|c|}
\hline Variables & Mean & Std. Dev. & Min & Max \\
\hline Sale Price & 142212.4 & 102970.2 & 25000 & 1856789 \\
\hline Logarithm of Sale Price (LnPrice) & 11.68524 & 0.577911 & 10.12663 & 14.43436 \\
\hline Asking Price & 115269.1 & 86071.91 & 17000 & 1100000 \\
\hline Natural Logarithm of Asking Price & 11.46685 & 0.58418 & 9.740969 & 13.91082 \\
\hline $\mathrm{km}$ to airport & 7.6964 & 2.3051 & 0.7224 & 16.1087 \\
\hline $\mathrm{km}$ to central train station & 3.1395 & 2.4477 & 0.0955 & 16.3279 \\
\hline Dwellings per hectare ${ }^{\wedge}$ & 48.8525 & 49.8203 & 0.0442 & 1052.7841 \\
\hline Detached houses & 0.1003 & 0.3004 & 0 & 1 \\
\hline Terraced/semi-detached house & 0.2674 & 0.4426 & 0 & 1 \\
\hline Ground/1st floor flat & 0.0009 & 0.0301 & 0 & 1 \\
\hline 2nd floor flat & 0.0606 & 0.2386 & 0 & 1 \\
\hline 3rd floor flat & 0.0055 & 0.0739 & 0 & 1 \\
\hline 4+ floor flat & 0.0017 & 0.0413 & 0 & 1 \\
\hline Missing info. on floor no & 0.3372 & 0.4728 & 0 & 1 \\
\hline 1 bedrooms & 0.2823 & 0.4501 & 0 & 1 \\
\hline 2 bedrooms & 0.3881 & 0.4873 & 0 & 1 \\
\hline 3 bedrooms & 0.2205 & 0.4146 & 0 & 1 \\
\hline 4 bedrooms & 0.0708 & 0.2565 & 0 & 1 \\
\hline 5 bedrooms & 0.0198 & 0.1392 & 0 & 1 \\
\hline $6+$ bedrooms & 0.0071 & 0.0839 & 0 & 1 \\
\hline Missing bedroom no & 0.0115 & 0.1064 & 0 & 1 \\
\hline $3+$ public rooms & 0.0814 & 0.2735 & 0 & 1 \\
\hline 2+ bathrooms & 0.0366 & 0.1878 & 0 & 1 \\
\hline Garage(s) & 0.2162 & 0.4117 & 0 & 1 \\
\hline Gas central heating & 0.7954 & 0.4034 & 0 & 1 \\
\hline Garden & 0.5148 & 0.4998 & 0 & 1 \\
\hline$>50 \%$ detached houses ${ }^{\mathrm{a}}$ & 0.0666 & 0.2493 & 0 & 1 \\
\hline$>50 \%$ terraced $/$ semi-detached $^{\mathrm{a}}$ & 0.2712 & 0.4446 & 0 & 1 \\
\hline Not dominated by any house type $\mathrm{a}^{\mathrm{a}}$ & 0.0674 & 0.2508 & 0 & 1 \\
\hline$>50 \%$ of social rented houses ${ }^{\mathrm{a}}$ & 0.0804 & 0.2719 & 0 & 1 \\
\hline$>50 \%$ of privately rented houses ${ }^{\mathrm{a}}$ & 0.0187 & 0.1355 & 0 & 1 \\
\hline$>20 \%$ of vacant household spaces ${ }^{a}$ & 0.0588 & 0.2353 & 0 & 1 \\
\hline
\end{tabular}


$>40 \%$ of the population over $60^{\mathrm{a}}$

0.0481

0.2140

0.2171

0.4123

0.1785

0.3830

0.0779

0.2681

$\begin{array}{ll}0 & 1 \\ 0 & 1 \\ 0 & 1 \\ 0 & 1\end{array}$

${ }^{a}$ These data were taken from 2001 UK Census and refer to the geographical level of an output area (OA). OA is the lowest spatial aggregation available for census data, with its average size in Scotland being 50 households. This is taken as an equivalent to a neighborhood.

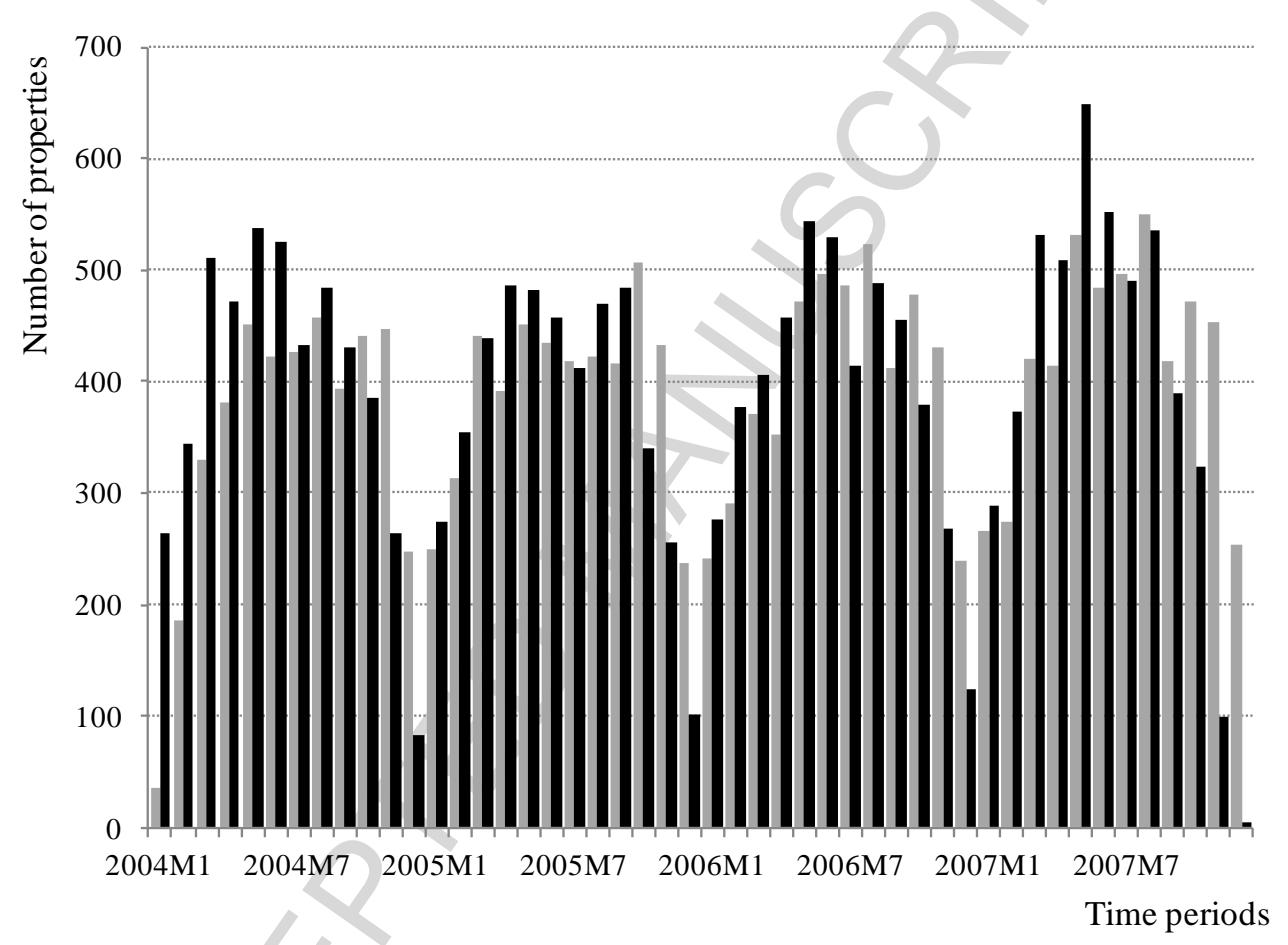

Figure 1: Number of sales (grey) and houses put on the market (black) per month 


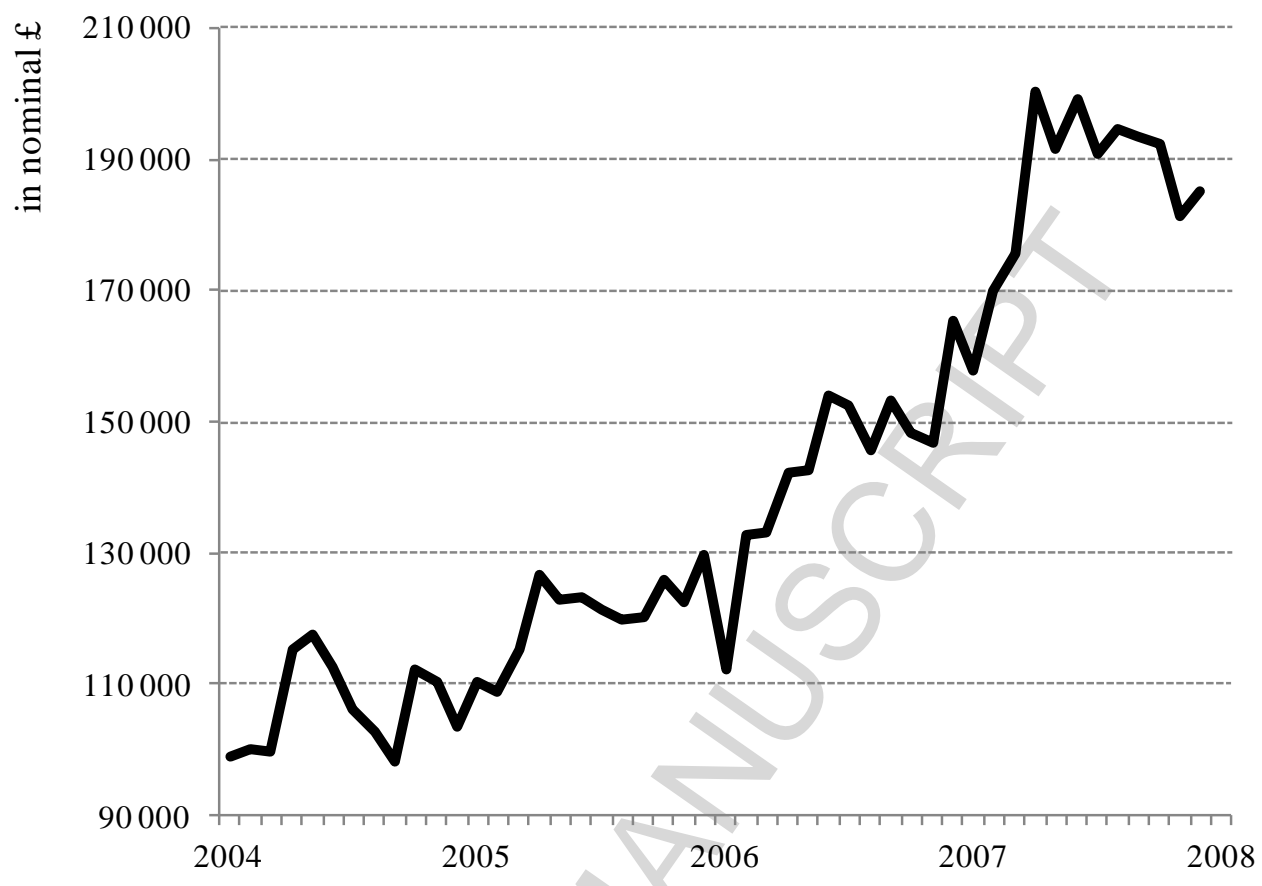

Figure 2: Evolution of the mean price of houses in Aberdeen, 2004-2007

\section{Modelling Results}

This section presents and discusses the results, according to a priory expectations and theoretical considerations with respect to the temporal dimension. The results of three models are presented in Table 4. STAR 1 model is the equivalent of the typical approach in the spatio-temporal literature (see Section 2.3), including only unidirectional effects in from past prices. STAR 2 provides the results from the full specification (equations 2, 16-17) that beside the "past comparable sales" effect also includes the "sellers' expectation" and "contemporaneous peer" effects. For completeness and comparison purposes, the results of a SAR model that misspecifies the DGP for spatio-temporal data through the spatial matrix $\mathbf{S}$ (eq. 5) are also shown. It is stressed that a cut-off distance and non-linear dissipation of the spatial connection (eq. 4) was introduced in the spatial matrices $\mathbf{S}$ and $\mathbf{W}$, so as to avoid extreme over-connection and spatial unit root issues when estimating SAR (Dubé and Legros, 2014).

The fit to the data is very good across all models, explaining about $79 \%$ of the variation, with all coefficients having the a priori expected signs and most being significant at the $95 \%$ level including the spatio-temporal effects $\psi, \rho$, and $\varphi$. As expected, proximity to central train 
station, higher floor number, more rooms, a garage, gas central heating, and a garden, attract a premium, as do detached, terraced and semi-detached houses compared to flats. Neighborhoods not dominated by a specific house type, with a higher percentage of residents over 60 , or dominated by multi-car ownerships levels are also at a premium. Conversely, house prices decrease at higher dwelling densities and proximity to the airport, or in neighborhoods dominated by terrace/semi-detached houses, socially or privately rented houses, one person households, non-car owning households, and high rates of vacant houses.

Table 4: Estimation results

\begin{tabular}{|c|c|c|c|c|c|c|}
\hline Depended Variable: Ln(Price) & $\begin{array}{c}\text { STAR 1 } \\
(\psi)\end{array}$ & & $\begin{array}{c}\text { STAR 2 } \\
(\psi \& \rho \& \varphi\end{array}$ & & $\begin{array}{c}\text { SAR } \\
\text { ( } \rho \text { misspecifie }\end{array}$ & \\
\hline Independent Variables & Coefficients & & Coefficients & & Coefficients & \\
\hline Constant & 9.4071 & $* *$ & 6.9403 & $* *$ & 10.7470 & $* *$ \\
\hline $\mathrm{km}$ to airport & 0.0139 & $* *$ & 0.0140 & $* *$ & 0.0139 & $* *$ \\
\hline $\mathrm{km}$ to central train station & -0.0369 & $* *$ & -0.0371 & $* *$ & -0.0369 & $* *$ \\
\hline Detached houses & 0.1108 & $* *$ & 0.1110 & $* *$ & 0.1108 & $* *$ \\
\hline Terraced/semi-detached house & 0.0238 & $* *$ & 0.0243 & $* *$ & 0.0238 & $* *$ \\
\hline Ground/1st floor flat & Reference & & Reference & & Reference & \\
\hline 2nd floor flat & 0.0074 & & 0.0072 & & 0.0078 & \\
\hline 3rd floor flat & 0.0844 & $* *$ & 0.0838 & $* *$ & 0.0836 & $* *$ \\
\hline 4+ floor flat & 0.1543 & $* *$ & 0.1558 & $* *$ & 0.1537 & $* *$ \\
\hline Missing info. on floor no & -0.0306 & $* *$ & -0.0304 & $* *$ & -0.0304 & $* *$ \\
\hline 1 bedrooms & -0.5122 & $* *$ & -0.5124 & $* *$ & -0.5124 & $* *$ \\
\hline 2 bedrooms & -0.1535 & $* *$ & -0.1535 & $* *$ & -0.1535 & $* *$ \\
\hline 3 bedrooms & Reference & & Reference & & Reference & \\
\hline 4 bedrooms & 0.2079 & $* *$ & 0.2075 & $* *$ & 0.2075 & $* *$ \\
\hline 5 bedrooms & 0.4030 & $* *$ & 0.4032 & $* *$ & 0.4029 & $* *$ \\
\hline $6+$ bedrooms & 0.6397 & $* *$ & 0.6370 & $* *$ & 0.6392 & $* *$ \\
\hline Missing bedroom no & -0.8397 & $* *$ & -0.8397 & $* *$ & -0.8395 & $* *$ \\
\hline $3+$ public rooms & 0.2698 & $* *$ & 0.2697 & $* *$ & 0.2699 & $* *$ \\
\hline $2+$ bathrooms & 0.1530 & $* *$ & 0.1541 & $* *$ & 0.1533 & $* *$ \\
\hline Garage(s) & 0.2029 & $* *$ & 0.2030 & $* *$ & 0.2029 & $* *$ \\
\hline Gas central heating & 0.1287 & $* *$ & 0.1285 & $* *$ & 0.1288 & $* *$ \\
\hline Garden & 0.0279 & $* *$ & 0.0281 & $* *$ & 0.0278 & $* *$ \\
\hline$>50 \%$ detached houses & -0.0159 & & -0.0166 & & -0.0158 & \\
\hline$>50 \%$ terraced $/$ semi-detached & -0.0447 & $* *$ & -0.0452 & $* *$ & -0.0446 & $* *$ \\
\hline Not dominated by any house type & 0.0659 & $* *$ & 0.0659 & $* *$ & 0.0660 & $* *$ \\
\hline$>50 \%$ of social rented houses & -0.1959 & $* *$ & -0.1962 & $* *$ & -0.1961 & $* *$ \\
\hline$>50 \%$ of privately rented houses & -0.0913 & $* *$ & -0.0908 & $* *$ & -0.0916 & $* *$ \\
\hline$>20 \%$ of vacant floor space & -0.0207 & $*$ & -0.0203 & $*$ & -0.0207 & $*$ \\
\hline$>40 \%$ of the population over 60 & 0.1054 & $* *$ & 0.1059 & $* *$ & 0.1056 & $* *$ \\
\hline$>60 \%$ of one person households & -0.0177 & $* *$ & -0.0180 & $* *$ & -0.0178 & $* *$ \\
\hline
\end{tabular}




\begin{tabular}{|c|c|c|c|c|c|c|}
\hline Depended Variable: Ln(Price) & \multicolumn{2}{|l|}{$\begin{array}{c}\text { STAR } 1 \\
(\psi)\end{array}$} & \multicolumn{2}{|c|}{$\begin{array}{c}\text { STAR 2 } \\
(\psi \& \rho \& \varphi)\end{array}$} & \multicolumn{2}{|c|}{$\begin{array}{c}\text { SAR } \\
\text { ( } \rho \text { misspecified) }\end{array}$} \\
\hline Independent Variables & Coefficients & & Coefficients & & Coefficients & \\
\hline$>50 \%$ owning $2+$ cars & 0.2196 & $* *$ & 0.2195 & $* *$ & 0.2195 & $* *$ \\
\hline$>50 \%$ no car & -0.1607 & $* *$ & -0.1610 & $* *$ & -0.1609 & $* *$ \\
\hline Dwellings per hectare & -0.0008 & $* *$ & -0.0008 & $* *$ & -0.0008 & $* *$ \\
\hline 2004 - Q1\&Q2 & Reference & & Reference & & Reference & \\
\hline 2004 - Q3 & -0.0382 & $* *$ & -0.0207 & $*$ & -0.0365 & $* *$ \\
\hline $2004-\mathrm{Q} 4$ & -0.0372 & $* *$ & -0.0319 & $* *$ & -0.0448 & $* *$ \\
\hline 2005 - Q1 & 0.0206 & & 0.0161 & & 0.0150 & \\
\hline 2005 - Q2 & 0.0777 & $* *$ & 0.0521 & $* *$ & 0.0851 & $* *$ \\
\hline $2005-\mathrm{Q} 3$ & 0.0720 & $* *$ & 0.0526 & $* *$ & 0.0855 & $* *$ \\
\hline $2005-\mathrm{Q} 4$ & 0.0943 & $* *$ & 0.0697 & $* *$ & 0.1085 & $* *$ \\
\hline 2006 - Q1 & 0.1763 & $* *$ & 0.1381 & $* *$ & 0.1921 & $* *$ \\
\hline 2006 - Q2 & 0.2510 & $* *$ & 0.1861 & $* *$ & 0.2809 & $* *$ \\
\hline $2006-\mathrm{Q} 3$ & 0.2977 & $* *$ & 0.2311 & $* *$ & 0.3400 & $* *$ \\
\hline $2006-Q 4$ & 0.3297 & $* *$ & 0.2561 & $* *$ & 0.3756 & $* *$ \\
\hline 2007 - Q1 & 0.4654 & $* *$ & 0.3630 & $* *$ & 0.5184 & $* *$ \\
\hline 2007 - Q2 & 0.5430 & $* *$ & 0.4118 & $* *$ & 0.6164 & $* *$ \\
\hline $2007-$ Q3 & 0.5048 & $* *$ & 0.3807 & $* *$ & 0.5886 & $* *$ \\
\hline $2007-\mathrm{Q} 4$ & 0.4851 & $* *$ & 0.3605 & $* *$ & 0.5720 & $* *$ \\
\hline \multicolumn{7}{|l|}{ Spatial or Spatiotemporal Effects } \\
\hline$\psi($ Comparable past sales effect) & 0.1843 & $* *$ & 0.1342 & $* *$ & & \\
\hline$\varphi$ (Future expectations effect) & & & 0.0644 & $*$ & & \\
\hline$\rho($ Contemporaneous peer effect $)$ & & & 0.2020 & $* *$ & 0.0660 & $* *$ \\
\hline $\mathrm{R}^{2}$ & 0.7886 & & 0.7886 & & 0.7885 & \\
\hline $\mathrm{R}^{2}-$ bar & 0.7881 & & 0.7881 & & 0.7880 & \\
\hline Final LL & 4510 & & 4529 & & 4506 & \\
\hline
\end{tabular}

Statistical Significance: $* * \mathrm{p}<0.01 ; * \mathrm{p}<0.05$

Comparing the STAR models to the misspecified SAR, the latter has the worst fit to the data, even though the relationships in the upper triangle of $\mathbf{S}$ matrix are not present in STAR 1. This indicates that the misspecified "time-travel" relationships in SAR do not contribute much to explaining the data. This is also reflected in the magnitude difference of $\rho$ coefficients between STAR2 and SAR. The contemporaneous peer effect within one month before the sale in STAR2 has a three times greater effect than in SAR where the contemporaneous peer effect lasts 4 years. The magnitude of most other coefficients does not differ significantly between the three models, except for the constant and the quarterly dummies. It seems that the temporal effects, lacking in SAR, are erroneously captured in the evolution of nominal house prices by the quarterly dummies. 
The preferred model, producing the best fit to the data, is STAR2. This presents empirical evidence consistent to hypotheses and the theoretical considerations in sections 1,3 and 4 . $t$ tests ${ }^{\mathrm{xv}}$ show that the three spatio-temporal effects are not equal to each other. The $\psi$ coefficient magnitude is a bit higher in STAR 1 than STAR 2, which is attributed to $\psi$ drawing on some of the variation explained by $\varphi$ and $\rho$ in STAR 2.

Discussing the results of the preferred model, the "comparable sales" coefficient of 0.13 means that a $£ 10,000$ increase in the prices of the previous period will cause an increase of $£ 1,342$ to the prices of the next period. The corresponding long run effect is 1.15 capturing the effect of past "comparable sales" on the current prices and the long run reactions to exogenous shock impacts on housing market. This will result in a long-run effect equal to $£ 1,550$, from a positive shock of a $£ 10,000$ increase, with a propagating impact equal to $£ 208$ beyond the first time period effect. It is noted $\psi$ encapsulates all the separate spatial, temporal and compound spatio-temporal effects in the $\mathbf{W}$ specification (see endnote 5) of Pace et al. (1998, 2000). The difficulties of Pace et al. (1998, 2000) specification are highlighted in Section 4.2 (see endnote 8 ), as we struggle to interpret the economic significance of separate spatial, temporal, and spatio-temporal effects between two observations. Furthermore, Pace et al. $(1998,2000)$ W specification fails to capture any of the two effects discussed below.

The effect of spatially weighted prices of other houses sold within the same period (month), captured in a $\rho$ of 0.2 , proxies for the impact of the contemporaneous peer interactions within the same period. For example, the shock of a $£ 10,000$ mean price increase in the vicinity will generate a raise of $£ 2,000$ in a given house price, if the effect is purely pecuniary. In the case of major exogenous technological shocks in the housing market, for instance new transport infrastructure (Dubé et al., 2014), the total effect of a $£ 10,000$ increase would be $£ 2,506$, resulting in a new spatial "steady state" equilibrium. However, no such major technological shocks are observed in the case study context, therefore the contemporaneous interactions are taken as purely pecuniary effects not requiring the spatial multiplier specification to estimate the total marginal effects. Given that this is the best proxy at our disposal for contemporaneous interactions not otherwise observed by the researcher, it is recognized that there might be an understandable simultaneity limitation in the current instrument. This limitation neither applies to the STAR1 model nor does it influence $\psi, \varphi$ or the $\beta$ s. 
Asking prices setting reflect the sellers' expectations about the future direction of prices, as discussed in Section 3. The hypothesis is that asking prices can affect final sale prices, due to strategic behavior and anchoring. This is addressed through the novel aspect of including spatio-temporally weighted asking prices of houses not yet sold, which is strictly an exogenous effect and can be interpreted here as an elasticity. The statistically significant $\varphi$ coefficient demonstrates that this indeed influences buyers' behavior and final sales prices. Its magnitude of 0.064 is, as expected, low compared to $\psi$ but not negligible, meaning that a mean asking price increase of $£ 10,000$ in the vicinity will cause an increase of $£ 644$ to the sale price in question. This evidence is the first instance in the literature that effects from beyond the own-house characteristics and own asking price are capitalized in the house prices. It is stressed that $\varphi$ has nothing to do with the attributes of the house itself.

Therefore, $\varphi$ can potentially be seen as a feedback mechanism that introduces into the hedonic price function (of the buyer) the expectations of increasing prices during a "boom" and potentially decreases during the "bust". It would also be interesting to see what happens to the $\varphi$ coefficient during the "bust" period in future research ${ }^{\mathrm{xvi}}$, given the "stickiness" of asking prices at the onset of an economic downturn (Haurin et al., 2013; Thanos and White, 2014). This could also capture expectations for local events, when major construction/improvement of local infrastructure is anticipated (McMillen and McDonald, 2004; Dubé et al., 2014).

\section{Conclusions}

Violations of the arrow of time and causality have been identified in spatial econometric techniques commonly applied to spatio-temporal data. A systematic review classifies several redresses to this issue, in a currently fragmented literature across fields with diverging terminology. It is not surprising that advances achieved in a currently fragmented literature across fields do not seem to reach the majority of spatial econometric applications in urban economics and regional science using this specific type of spatiotemporal data.

A robust methodological framework is developed by using the temporal dimension in spatial weights as a vehicle for identifying relationships underpinned by economic theory. The 
application of this framework indicated a STAR model and a Hadamard matrical product as the appropriate specifications here for testing the three hypotheses in this paper.

These research hypotheses are found to be statistically significant, providing estimates for the following distinct economic processes at work. The comparable sales approach is valid in a spatio-temporal setting. Past comparable sales have indeed an effect on current prices. Testing the hypothesis about "sellers' expectations" required the development of a unique STAR specification. This is the first instance in the literature that effects other than the own asking price can be handled in such models. The signals of sellers' expectations are captured in the asking prices of other houses not yet sold (still on the market at the time of the sale). These influence buyers' behavior and the final prices, due to strategic thinking and anchoring, by an estimated elasticity of 0.064 . This is a mechanism that introduces the increasing price expectations in "boom" market conditions to the hedonic price function. Therefore, it can be interpreted as one of the mechanisms that can potentially sustain housing market "bubbles".

There is also a statistically significant proxy for the contemporaneous peer effect, when the buyer interacts with other buyers/seller either directly or through market intermediaries. Due to data constraints, there might be simultaneity limitation with current instruments, which are addressed to a degree by the limited timeframe and scope of the effect, but the need for further development is recognized.

The surge in the importance and applicability of spatio-temporal approaches is underlined here. These approaches ought to rapidly continue gaining prominence, given the methodological advances and constant computational power increase. Hence, the innovations in this paper are important for further empirical research not only in the housing market, but also extension to other contexts/fields that spatio-temporal data are available, for instance energy efficiency retrofits, innovation, business starts, and crime events.

There are also quite a few avenues of future research, for instance methodological advances in optimally estimating and combining temporal and spatial relationships in spatio-temporal weights (Seya et al., 2013). The uncertainty about DGP assumptions could also be initially addressed by adapting Lagrange multiplier tests (Pede et al., 2014) in terms of optimal model selection for spatiotemporal data. McMillen (2010, 2012) and McMillen and Redfearn (2010) 
demonstrate the advantages of nonparametric models that are feasible and highly applicable to spatial HP models. Hence, an interesting research avenue is to further develop and potentially combine the current spatial semiparametric approaches (Huang et al., 2010; Wrenn and Sam, 2014) to parametric approaches that capture the spatio-temporal information effects.

Concluding, we are calling for a systematic approach to spatio-temporal data analysis in applied economics, formalizing this currently "fragmented" field. 


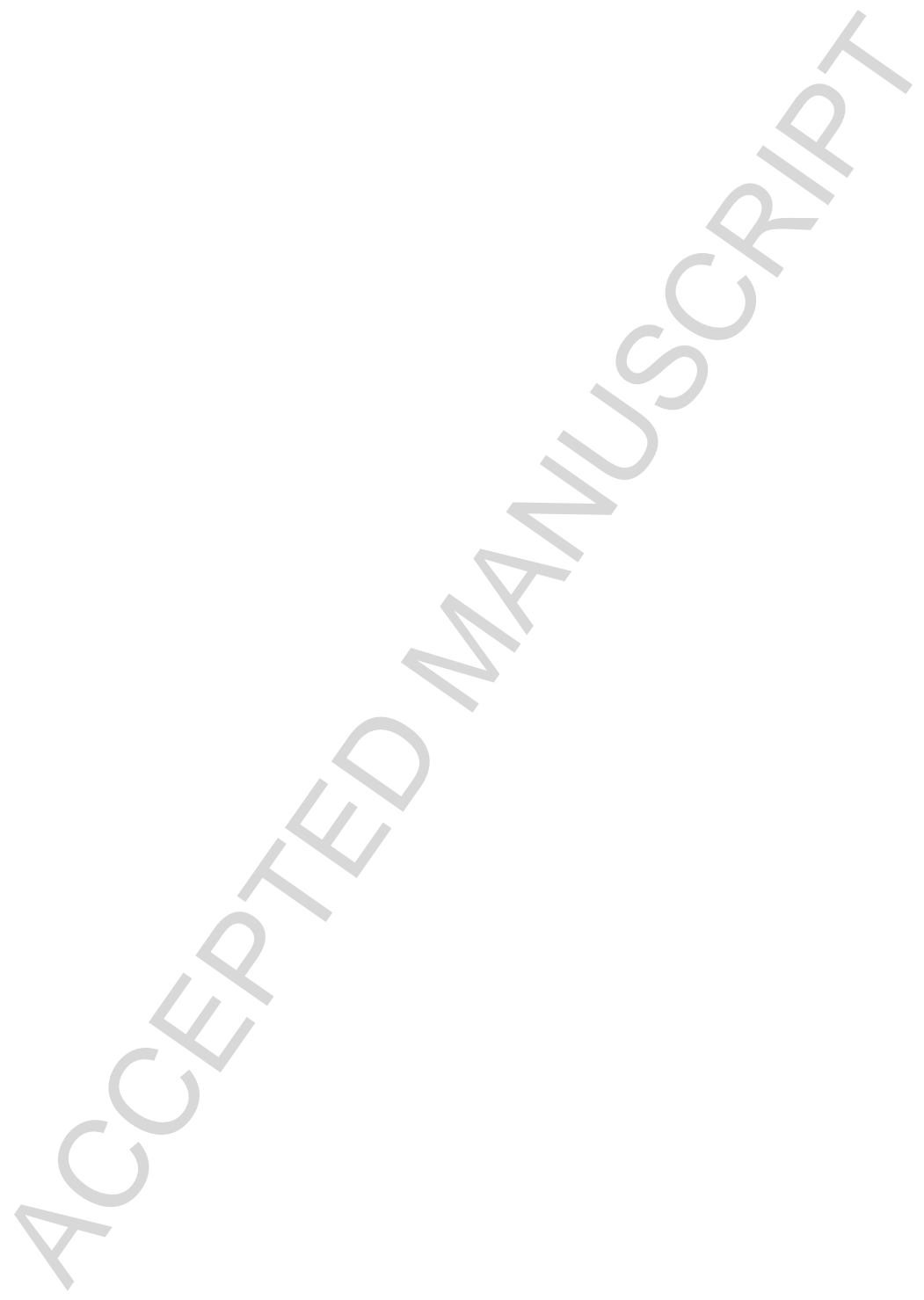




\section{References}

Alberto, I., Beamonte, A., Gargallo, P., Mateo, P.M., Salvador, M., 2010. Variable Selection in STAR Models with Neighbourhood Effects Using Genetic Algorithms, Journal of Forecasting 29, 728-750

Andersson, H., Jonsson, L., and Ögren, M., 2010. Property prices and exposure to multiple noise sources: Hedonic regression with road and railway noise, Environmental and resource economics 45, 73-89.

Anselin, L., 2010. Thirty years of spatial econometrics, Papers in Regional Science 89, 3-25

Beamonte, A., Gargallo, P., Salvador, M. J., 2008. Bayesian Inference in STAR Models using Neighborhood Effects, Statistical Modelling 8, 285-311.

Beamonte, A., Gargallo, P., Salvador, M. J., 2010a. Analysis of Housing Price by Means of STAR Models with Neighbourhood Effects: A Bayesian Approach, Journal of Geographical Systems, 12:2, 227-40.

Beamonte, A., Gargallo, P., Salvador, M. J., 2010b. Robust Bayesian Inference in STAR Models with Neighbourhood Effects. Journal of Statistical Planning and Inference, 2010b. 140:11, 3047-57.

Beamonte, A., Gargallo, P., Salvador, M. J., 2013. Retrospective Analysis of the Dwelling Price by Means of STAR Models with Neighborhood Effects. Journal of Real Estate Research 35(2), 173-197

Black, R. T., Diaz III, J., 1996. The use of information versus asking price in the real property negotiation process, Journal of Property Research 13, 287-297

Brandt, S., Maennig W., 2011. Road noise exposure and residential property prices: Evidence from Hamburg, Transportation Research Part D 16, 23-30

Briant, A., Combes, P.P., Lafourcade, M., 2010. Dots to boxes: Do the size and shape of spatial units jeopardize economic geography estimations?, Journal of Urban Economics 67, 287-302

Can, A., Megbolugbe, I., 1997. Spatial dependence and house price index construction, Journal of Real Estate Finance and Economics 14, 203-222.

Cohen, J.P., Coughlin, C.C., 2008. Spatial hedonic models of airport noise, proximity, and housing prices, Journal of regional science 48, 859-878

Conway, D., Li, C. Q., Wolch, J., Kahle, C., Jerrett M., 2010. A spatial autocorrelation approach for examining the effects of urban greenspace on residential property values, Journal of Real Estate Finance and Economics 41, 150-169. 
Diaz III, J., Zhao, R., Black, R., 1999. Does contingent reward reduce negotiation anchoring?, Journal of Property Investment and Finance 17(4), 374-379

Dubé, J., Legros, D., 2013a. A spatio-temporal measure of spatial dependence: An example using real estate data, Papers in Regional Science 92, 19-30

Dubé, J., Legros, D., 2013b. Dealing with spatial data pooled over time in statistical models, Letters in Spatial and Resource Sciences 6, 1-18.

Dubé, J., Legros, D., 2014. Spatial econometrics and the hedonic pricing model: what about the temporal dimension?, Journal of Property Research 31(4), 333-359

Dubé, J., Legros, D., Thériault, M., Des Rosiers, F. (2014). A Spatial Difference-inDifferences Estimator to Evaluate the Effect of Change in Public Mass Transit Systems on House Prices, Transportation Research Part B, 64: 24-40.

Dunse, N., Thanos, S., Bramley, G., 2013. Planning Policy, Housing Density and Consumer Preferences, Journal of Property Research 30, 221-238

Gelfand, A.E., Ghosh, S.K., Knight, J.R., Sirmans, C.F., 1998. Spatio-temporal modeling of residential sales markets, Journal of Business and Economic Statistics 16, 312-321

Gelfand, A.E., Kim, H.J., Sirmans, C.F., Banerjee, S., 2003. Spatial Modeling with Spatially Varying Coefficient Processes, Journal of the American Statistical Association 98, 387-396

Gelfand, A.E., Ecker, M.D., Knight, J.R., Sirmans, C.F., 2004. The dynamics of location in home price, Journal of Real Estate Finance and Economics 29, 149-166.

Halleck Vega, S., Elhorst J. P., 2015. The SLX Model. Journal of Regional Science 55(3), $339-363$

Haurin, D., McGreal, S., Adair, A., Brown, L., Webb, J.R., 2013. List price and sales prices of residential properties during booms and busts, Journal of Housing Economics 22, 1-10

Huang, B., Wu, B., Barry, M., 2010. Geographically and temporally weighted regression for modeling spatiotemporal variation in house prices, International Journal of Geographical Information Science 24(3), 383-401

Hui, E.C.M., Yu, K.H., 2012. The impact of pricing strategies on time-on-market under various economic conditions, International Journal of Strategic Property Management 16, 56-70

Isakson, H.R., 2002. The Linear Algebra of the Sales Comparison Approach, Journal of Real Estate Research 24, 117-128. 
Kuminoff, N. V., Jarrah, A. S., 2010. A new approach to computing hedonic equilibria and investigating the properties of locational sorting models, Journal of Urban Economics 67, $322-335$

Le Gallo, J., 2002. Économétrie spatiale: l'autocorrélation spatiale dans les modèles de régression linéaire [Spatial econometrics: Spatial autocorrelation in linear regression models], Économie et prévision 155, 139-157

LeSage, J.P., 2014. What Regional Scientists Need to Know about Spatial Econometrics, The Review of Regional Studies, 44, 13-32

LeSage, J. P., Pace, K. R. 2009. Introduction to spatial econometrics. NY: CRC Press, New York, US

Liu, X., 2013. Spatial and Temporal Dependence in House Price Prediction, Journal of Real Estate Finance and Economics 47, 341-369

McMillen, D., McDonald, J., 2004. Reaction of house prices to a new rapid transit line: Chicago's midway line, 1983-1999. Real Estate Economics 32 (3), 463-486.

McMillen, D.P., Redfearn, C.L., 2010. Estimation and hypothesis testing for nonparametric hedonic house price functions. Journal of Regional Science 50(3): 712-733.

McMillen, D.P., 2010. Issues in Spatial Data Analysis, Journal of Regional Science 50, 119141.

McMillen, D.P., 2012. Perspectives on Spatial Econometrics: Linear Smoothing with Structured Models, Journal of Regional Science 52(2), 192-20.

Muth, J., 1961. Rational Expectations and the Theory of Price Movements, Econometrica 29, $315-35$

Nappi-Choulet, I., Maury, T.-P., 2009. A spatiotemporal autoregressive price index for the Paris office property market, Real Estate Economics 37(2), 305-340

Nappi-Choulet, I., Maury, T.-P., 2011. A spatial and temporal autoregressive local estimation for the Paris housing market, Journal of Regional Science 51(4), 732-750

Pace, R.K., Barry, R., Clapp, J. M., Rodriquez, M., 1998. Spatiotemporal Autoregressive Models of Neighborhood Effects, Journal of Real Estate Finance and Economics 17, 15-33

Pace, R.K., Barry, R., Gilley, O.W., Sirmans, C.F., 2000. A method for spatial-temporal forecasting with an application to real estate prices, International Journal of Forecasting 16, $229-246$ 
Pede, V.O., Florax, R.J.G.M., Lambert, D.M., 2014. Spatial econometric STAR models: Lagrange multiplier tests, Monte Carlo simulations and an empirical application, Regional Science and Urban Economics, 49, 118-128

Pryce, G., Gibb, K., 2006. Submarket dynamics of time to sale. Real estate economics, 34, $377-415$.

Salvi, M., 2008. Spatial estimation of the impact of airport noise on residential housing prices, Swiss journal of economics and statistics 2008-IV-3, 577-606

Seo, K., Golub, A., Kuby, M., 2014. Combined impacts of highways and light rail transit on residential property values: a spatial hedonic price model for Phoenix, Arizona, Journal of Transport Geography, 41, 53-62

Seya, H., Yamagata, Y., Tsutsumi, M., 2013. Automatic selection of a spatial weight matrix in spatial econometrics: Application to a spatial hedonic approach, Regional Science and Urban Economics, 43 (3), 429-444

Scott, P., Lizieri, C., 2012. Consumer house price judgments: new evidence of anchoring and arbitrary coherence, Journal of Property Research 29, 49-68

Small, K. A., Steimetz, S.S.C., 2012. Spatial Hedonics and the Willingness to Pay for Residential Amenities, Journal of Regional Science 52, 635-647

Smith, T.E., 2009. Estimation Bias in Spatial Models with Strongly Connected Weight Matrices, Geographical Analysis 41, 307-332

Smith, T.E., Wu, P., A spatio-temporal model of housing prices based on individual sales transactions over time, Journal of Geographical Systems 11(4), 333-355

Sun, H., Tu, Y., Yu, S.M., 2005. A spatio-temporal autoregressive model for multi-unit residential market analysis, The Journal of Real Estate Finance and Economics 31, 155-187

Thanos, S., Bristow, A. L., Wardman, M. R., 2012. Theoretically consistent temporal ordering specification in spatial hedonic pricing models applied to the valuation of aircraft noise, Journal of Environmental Economics and Policy 1(2), 103-126.

Thanos, S., White, M. 2014. Expectation Adjustment in the Housing Market: Insights from the Auction System in Scotland. Housing Studies, 29 (3), 339-361

Thanos, S., Bristow A. L., Wardman, M. R. (2015), Residential sorting and environmental externalities: the case of non-linearities and stigma in aviation noise values, Journal of Regional Science 55(3), 468-490

Tu, Y., Yu, S.M., Sun, H., 2004. Transaction-based office price indexes: A spatiotemporal modeling approach, Real Estate Economics 32, 297-328 
Tversky, A., Kahneman, D., 1974. Judgment under uncertainty: heuristics and biases, Science $185,1124-1131$.

Wrenn, D. H., Sam, A. G., 2014. Geographically and temporally weighted likelihood regression: Exploring the spatiotemporal determinants of land use change, Regional Science and Urban Economics, 44, 60-74

Yavas, A., Yang, S., 1995. The strategic role of listing price in marketing real estate: theory and evidence, Real Estate Economics 23(3), 347-368.

Zuehlke, T.W., 1987. Duration dependence in the housing market. The review of economics and statistics, 69, 701-709. 


\section{Acknowledgements}

We are grateful to the Aberdeen Solicitors Property Centre and Michael White for making the data available for this research. We owe thanks Mark Wardman and Abigail Bristow for their insights and help. Jean Dubé thanks the Fonds de recherche québécois Société et Culture (FRQSC) for the financial support through the young researcher instalment programs. The content of the paper and any opinions expressed are the sole responsibility of the authors. 


\section{Highlights}

- "Arrow of time" violations in a spatial econometric subfield are examined.

- A temporal-structure framework to spatial relations addresses these violations.

- The framework isolates three distinct economic processes in the housing market.

- $\quad$ The processes are: comparable price effects; sellers' expectations; peer effects.

${ }^{\mathrm{i}}$ In spatial econometrics, the $\mathrm{W}$ matrix defines the spatial interactions between observations. It is exogenously defined and usually based on Euclidean distance.

${ }^{i i}$ For instance, data on house prices/sales, energy efficiency retrofits, innovation, business starts, and, crime events are spatiotemporal. However, we have found only house prices/sales data are being utilized in spatiotemporal econometric analysis.

iii This includes spatial data pooled over different time periods.

iv The distortions arising from the choice of a specific zoning system employed for spatial aggregation. Briant et al (2010) found that indeed the size of the spatial aggregation unit can distort estimation results.

${ }^{v}$ If final sale prices were observable by peers, the effect would immediately become a unidirectional comparable sales effect.

${ }^{v i}$ The discussion here addresses the Spatial Autoregressive specification. In the case of a misspecified Spatial Error Model for spatio-temporal data, time-invariant residuals from unknown sources are assumed have a spatial distribution affecting the IID properties. Nevertheless, it makes no sense to use the symmetric spatial weight matrix $\mathbf{W}$ to account for time-invariant residuals in data that have a temporal dimension. Time-invariant unobserved effects influence both past and future in the same way and should be accounted for by a separate time-invariant error term (Smith and $\mathrm{Wu}, 2009$ ), not by spatially weighting residuals of sales that have not happened yet.

${ }^{\text {vii }}$ In solving the temporal dimension issue, it is common to estimate HP models using a panel treatment to account for the $t$ subscript. The resulting panel dataset is a compilation of house attributes' means for sales in each spatio-temporal unit. In panel specification, the $\boldsymbol{y}$ and $\boldsymbol{\varepsilon}$ vectors are of dimension $(N T \times 1)$, while the matrix $\mathbf{X}$ is of $\operatorname{dimension}(N T \times(K+1))$, where $N$ is the total number of spatial aggregation units, while $T$ is the total number of time period. However, this approach requires temporal and spatial aggregation of spatio-temporal data. The spatial aggregation reduces the total variance in the data, treats means as exogenous/independent observations, and introduces MAUP. 
viii This can be viewed as a Hadamard product of a symmetric spatial distance matrix $\mathbf{S}$ and a simple temporal lower triangular matrix $\mathbf{T}$. The elements of $\mathbf{T}$ take the value of 1 only for previous sales within 6 months and 0 otherwise.

ix This combination of the spatial and temporal matrices is specified as the spatiotemporal matrix $\mathbf{W}=\varphi_{T} \mathbf{T}+\varphi_{S} \mathbf{S}+\varphi_{S T} \mathbf{S} \mathbf{T}+\varphi_{T S} \mathbf{T S}$

${ }^{\mathrm{x}}$ High proportion of zeros in the matrix.

${ }^{x i}$ There is no a priory expectation for the HP function of house $i$ to contain spatio-temporally weighted observations of the attributes $\mathbf{W} \boldsymbol{x}_{\zeta}$ of another house $\zeta\left(y_{\zeta} \in\left\{y_{j(t-p)} \vee y_{h t} \vee\right.\right.$ $y_{m(t+q)} *$ If the attributes $\boldsymbol{x}_{\zeta}$ produce the observable effects $\boldsymbol{o}$ on house $i$ at time $t$ of the sale, then $\boldsymbol{o}_{i t}$ are included in the observable house attributes $\boldsymbol{x}_{i t}$ or in the "own house price" $y_{\zeta}$, or in an unobservable spatially weighted error term. If the effects $\boldsymbol{o}$ are not observed by the buyer, they cannot affect the final price $y_{i t}$. Hence, STDM or STLX modelling approaches are not applied to the spatiotemporal housing data here. STEM is possible, but addresses the special case of either a new-built house $\zeta$ or an improvement/deterioration to house $\zeta$ after its last sale. A STEM in HP is relevant when data is mostly comprised of new-build houses or extensive house improvements as in Thanos et al., (2015). This is not the case with our data.

xii This approach initially proposed by Pace et al. $(1998,2000)$ and there are some the issues with it. Distinct spatial and temporal autoregressive terms (see footnote 4) mean that house $i$ can be dependent on the spatially weighted observation of house $h$ and at the same time on the temporally weighted observation of house $h$. Whereas, house $i$ can be dependent on the spatially weighted observation of house $j$, but not on the temporally weighted observation of house $j$ and vice versa. This specification also implies that the same observation $h$ has two separate existences that affect $i$, one the spatial and another in the temporal dimension. We contend that space-time is a continuum. A corollary is that ST and TS are different and are explained as compound spatio-temporal effects (Smith and $\mathrm{Wu}, 2009$ ). We struggle to interpret their economic significance, as their coefficients are often negative and rarely significant, thus this specification appears to be an artefact of using simple matrix multiplication.

\footnotetext{
${ }^{\text {xiii }}$ High proportions of zeroes in the weight matrix

${ }^{x i v}$ Each observations has at least one (spatio-temporal) neighbour or connection

${ }^{\mathrm{xv}}$ Asymptotic t-tests reject at the 95\% level the null hypotheses: $\rho-\psi=0, \rho-\varphi=0$, and $\psi-$ $\varphi=0$
} 
xvi The data in Aberdeen is during the "boom" period (see Figure 2) and do not allow this. 